\title{
High sensitivity of tropical precipitation to local sea-surface temperature
}

Article

Accepted Version

Good, P., Chadwick, R., Holloway, C. E. ORCID:

https://orcid.org/0000-0001-9903-8989, Kennedy, J., Lowe, J. A., Roehrig, R. and Rushley, S. S. (2020) High sensitivity of tropical precipitation to local sea-surface temperature. Nature, 589 (7842). pp. 408-414. ISSN 0028-0836 doi:

https://doi.org/10.1038/s41586-020-2887-3 Available at https://centaur.reading.ac.uk/93705/

It is advisable to refer to the publisher's version if you intend to cite from the work. See Guidance on citing.

Published version at: https://www.nature.com/articles/s41586-020-2887-3

To link to this article DOI: http://dx.doi.org/10.1038/s41586-020-2887-3

Publisher: Nature Publishing Group

All outputs in CentAUR are protected by Intellectual Property Rights law, including copyright law. Copyright and IPR is retained by the creators or other copyright holders. Terms and conditions for use of this material are defined in the End User Agreement.

\section{www.reading.ac.uk/centaur}

\section{CentAUR}


Central Archive at the University of Reading

Reading's research outputs online 


\section{High sensitivity of tropical precipitation to local sea-surface}

\section{2 temperature}

3

4 Peter Good $^{1 *}$, Robin Chadwick ${ }^{1,2}$, Christopher E. Holloway ${ }^{3}$, John Kennedy ${ }^{1}$, Jason A.

$5 \quad$ Lowe $^{1,4}$, Romain Roehrig ${ }^{5}$, Stephanie S. Rushley ${ }^{6}$

6

$7 \quad{ }^{1}$ MetOffice Hadley Centre, Exeter, United Kingdom.

$8 \quad{ }^{2}$ Global Systems Institute, University of Exeter.

$9 \quad{ }^{3}$ Department of Meteorology, University of Reading, Reading, United Kingdom.

$10{ }^{4}$ Priestley International Centre for Climate, University of Leeds, United Kingdom.

$11{ }^{5} \mathrm{CNRM}$, Université de Toulouse, Météo-France, CNRS, Toulouse, France

$12{ }^{6}$ Department of Atmospheric Sciences, University of Washington, Seattle, Washington 1398195, USA.

18 Precipitation and atmospheric circulation are the coupled processes through which tropical

19 ocean surface temperatures drive global weather and climate ${ }^{1-5}$. Local ocean surface warming tends to increase precipitation, but this local control is hard to disentangle from 
remote effects of conditions elsewhere. Such remote effects occur, for example, from El

Niño Southern Oscillation (ENSO) events in the equatorial Pacific, which alter precipitation across the tropics. Atmospheric circulations associated with tropical precipitation are predominantly deep, extending up to the tropopause. Shallow atmospheric circulations ${ }^{6-8}$, impacting the lower troposphere, also occur, but the importance of their interaction with precipitation is unclear. Uncertainty in precipitation observations ${ }^{9,10}$, and limited observations of shallow circulations ${ }^{11}$, further obstruct understanding of the ocean's influence on weather and climate. Despite decades of research, persistent biases remain in many numerical model simulations ${ }^{12-18}$, including excessively-wide tropical rainbands ${ }^{14,18}$, the

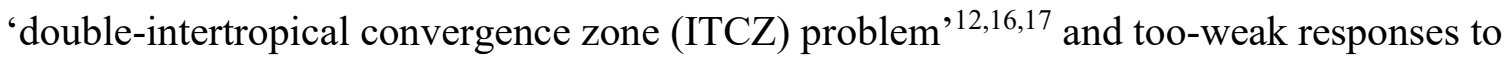
$\mathrm{ENSO}^{15}$. These demonstrate stubborn gaps in our understanding, reducing confidence in forecasts and projections. Here we show that the real world has a high sensitivity of seasonal tropical precipitation to local sea-surface temperature. Our best observational estimate is $80 \%$ precipitation change per $\mathrm{g} / \mathrm{kg}$ change in the saturation specific humidity (itself a function of the ocean surface temperature). This observed sensitivity is higher than in 43 of the 47 climate models studied, and is associated with strong shallow circulations. Models with more realistic sensitivity have smaller biases across a wide range of metrics. Our results apply to both temporal and spatial variation, over regions where climatological precipitation is around $1 \mathrm{~mm} /$ day or greater. Novel analysis of multiple independent observations, physical constraints and model data, underpin these findings. The spread in model behaviour is further linked to differences in shallow convection, providing a focus for accelerated research, to improve seasonal forecasts through multidecadal climate projections. 
47 We first define a measure $\left(\mathrm{k}_{\mathrm{qsat}}\right)$ of the sensitivity of seasonal mean precipitation to variation in local sea surface temperature (SST). We will show that $\mathrm{k}_{\mathrm{qsat}}$ is a key property of the atmosphere, using it to link diverse gaps in understanding to a limited subset of physical mechanisms. Precipitation increases non-linearly with $\mathrm{SST}^{19}$. Since tropical precipitation increases roughly exponentially with column atmospheric water vapour ${ }^{20,21}$; and over seasonal or longer timescales, SST variation forces variation in column water vapour ${ }^{22}$, via differences in saturation specific humidity of the ocean surface ( $\mathrm{q}_{\mathrm{sat}}$, Methods), we define $\mathrm{k}_{\mathrm{qsat}}$ as follows:

$\log _{\mathrm{e}}\left(\mathrm{P}_{1} / \mathrm{P}_{\underline{0}}\right) \approx \mathrm{k}_{\mathrm{qsat}} *\left(\mathrm{q}_{\mathrm{sat}, 1}-\mathrm{q}_{\mathrm{sat}, 0}\right)+<$ other processes $>$ Equation 1.

This describes the variation in precipitation (from $\mathrm{P}_{0}$ to $\mathrm{P}_{1}$ ) driven by local variation in $\mathrm{q}_{\mathrm{sat}}$ (from $\mathrm{q}_{\mathrm{sat}, 0}$ to $\mathrm{q}_{\mathrm{sat}, 1}$ ). This approximation is validated within the calculation of $\mathrm{k}_{\mathrm{qsat}}$ (Methods). Moist static energy arguments ${ }^{19}$ also predict a roughly exponential relationship between $\mathrm{q}_{\mathrm{sat}}$ and P. $\mathrm{k}_{\mathrm{qsat}}$ quantifies the combined effect of the physical processes by which local SST anomalies affect precipitation at the same location. The 'other processes' term includes the effects of internal atmospheric variability independent of SST, and of remote forcing from land or SST elsewhere, which can be large at individual locations or times. In order to estimate $\mathrm{k}_{\mathrm{qsat}}$, we filter out these other processes, by combining information from multiple locations and times (see Methods). We evaluate $\mathrm{k}_{\mathrm{qsat}}$ from interannual variability, with $\mathrm{P}_{\mathbf{0}}$ and $\mathrm{q}_{\mathrm{sat}, 0}$ taken as seasonal climatological means at each location for each season. However, our estimates of $\mathrm{k}_{\mathrm{qsat}}$ are shown to be also informative about spatial variations in precipitation. 
69

70

71

72

$\mathrm{k}_{\mathrm{qsat}}$ relates most directly to the strength of percentage variations in precipitation. Writing Equation 1 in exponential form, percentage precipitation differences are a function of $\mathrm{k}_{\mathrm{qsat}}$ and $\mathrm{q}_{\mathrm{sat}}$ :

$\left(\mathrm{P}_{1}-\mathrm{P}_{0}\right) / \mathrm{P}_{0} * 100 \approx 100\left[\exp \left(\mathrm{k}_{\mathrm{qsat}} *\left(\mathrm{q}_{\mathrm{sat}}-\mathrm{q}_{\mathrm{sat}, 0}\right)\right)-1\right]$.

Equation 2

Absolute differences depend also on the reference precipitation $\mathrm{P}_{0}$ :

$\mathrm{P}_{1}-\mathrm{P}_{0} \approx \mathrm{P}_{0}\left[\left(\exp \left(\mathrm{k}_{\mathrm{qsat}} *\left(\mathrm{q}_{\mathrm{sat}}-\mathrm{q}_{\mathrm{sat}, 0}\right)\right)-1\right]\right.$, Equation 3

(in absolute terms, precipitation variations are largest in regions of large mean precipitation ${ }^{19}$. However, we will show that spatial variation in $\mathrm{P} 0$ itself also depends partly on $\mathrm{k}_{\mathrm{qsat}}$.

\section{Validating satellite observations}

Given uncertainty in precipitation observations ${ }^{9,10}$, we perform a high-precision evaluation of $\log$ (precipitation) (as Equation 1) from two satellite datasets: TRMM ${ }^{23,24}(3 \mathrm{~B} 43, \mathrm{v} 7)$ and $\operatorname{GPCP}^{25}$ (v2.3), both for 1998-2015. We do this (Methods) using in-situ raingauge data from 89 buoys of the Global Tropical Moored Buoy Array (GTMBA) ${ }^{26-28}$. Satellite-GTMBA validation is challenging: on top of satellite error ${ }^{9}, 10$, the GTMBA point observations include noise from small-scale variability unresolved by satellite data, missing data, error in individual raingauges and wind undercatch ${ }^{29}$. Our method reduces this noise considerably, giving a tight relationship between GTMBA and TRMM data (Figure 1a). Critically, the best fit gradient $\approx 1$, so TRMM accurately retrieves differences in log precipitation. On the other hand, GPCP underestimates differences in $\log$ precipitation (Figure 1b, gradient $>1$; differences between TRMM and GPCP emerge primarily at low precipitation ${ }^{9}$ ), although GPCP is more suitable over larger spatial scales (Extended data Figure 1). Since TRMM captures differences in $\log ($ precipitation) more accurately than GPCP, TRMM is used below. 


\section{Model precipitation simulations}

94

We first highlight precipitation biases in 28 atmospheric models from the fifth Coupled Model Intercomparison Project (Methods), each forced by observed SST (CMIP5 AMIP experiment; Figure 2a-f). We quantify temporal, seasonal and spatial variation in precipitation: the 1997-98 El Niño divided by the mean of the 1998-2000 La Niñas; Aug-Oct divided by Feb-Mar seasons, and precipitation scaled by its latitudinal maximum. Our metrics coincide with significant spatial or temporal differences in SST (Methods). Spatial variation across the west Pacific is excluded, for example, because spatial gradients in SST are weak there, so model differences in $\mathrm{k}_{\mathrm{qsat}}$ will be less important for spatial variation there. Given the form of Equation 1, precipitation is shown on log scales as ratios. Although some models are close to the observations, in others, biases exceed a factor of five in the El Niño/La Niña ratio, seasonal cycles over the Atlantic and West Pacific, and in the Atlantic spatial pattern for the Aug-Oct season (Figure 2a-d). Biases over a factor of two occur in the spatial patterns of the East Pacific annual mean (the long-standing 'double-ITCZ' problem $^{12,17}$ ) and the Indian Ocean for November-April (Figure 2e-f). Such biases are known, but their causes are not well understood.

These biases (Figure 2a-f) all correspond to excessively weak spatial/temporal variations in precipitation (precipitation ratios too close to 1; including excessively-wide inter-tropical convergence zones $\left.{ }^{14,18}\right)$. This suggests a hypothesis $\left(\mathrm{H}_{0}\right)$, that the sensitivity of seasonal precipitation to local SST ( $\left.\mathrm{k}_{\mathrm{qsat}}\right)$ may be too weak in many models. 
115 To test $\mathrm{H}_{0}$ objectively, we use a method independent of Figure 2 (Figure 2 was used to 116 propose $\mathrm{H}_{0}$ ). This involves estimating $\mathrm{k}_{\mathrm{qsat}}$ for each model using different data.

118 Evaluating $\mathbf{k}_{\mathbf{q} s a t}$ in models

119 We evaluate $\mathrm{k}_{\mathrm{qsat}}$ using interannual variability in seasonal mean precipitation and SST (the 120 AMIP SST dataset ${ }^{30}$ used to drive the model experiments; using years 1980-2005). $\mathrm{k}_{\mathrm{qsat}}$ is 121 calculated using gridpoint values of seasonal precipitation and $\mathrm{q}_{\text {sat }}$, from each location in the study region, and for each year. With these data, Equation 1 becomes a model of the effect of local interannual SST variability on precipitation:

$\log _{\mathrm{e}}\left(\mathrm{P}(\mathrm{x}, \mathrm{t}) / \mathrm{P}_{0}(\mathrm{x})\right) \approx \mathrm{k}_{\mathrm{qsat}} *\left(\mathrm{q}_{\mathrm{sat}}(\mathrm{x}, \mathrm{t})-\mathrm{q}_{\mathrm{sat}, 0}(\mathrm{x})\right)+<$ other processes $>$,

where $(\mathrm{x}, \mathrm{t})$ indicates values for each gridpoint and year; and here, $\mathrm{P}_{0}$ and $\mathrm{q}_{\mathrm{sat}, 0}$ are the corresponding climatological means for each gridpoint. We estimate $\mathrm{k}_{\mathrm{qsat}}$ from these data using a modified regression approach (detailed in Methods), minimising the influence of other processes in Equation 1.

To minimise observational error, we exclude the $30 \%$ of the tropical oceans with the lowest climatological mean SST (Figure 3b-e, area outside white contour).

Taking logarithms means that all areas of our study region contribute relatively equally to our $\mathrm{k}_{\mathrm{qsat}}$ estimate (Methods). Consequently, $\mathrm{k}_{\mathrm{qsat}}$ is relevant over most of the tropical oceans (Figure 3a, correlations are high except for the left bar). $\mathrm{k}_{\mathrm{qsat}}$ is inapplicable over the coolest, 
Equation 4 
Expressed this way, the precipitation sensitivity in CMIP5 models spans 30-93\% per g/kg $($ median $=58 \%)$. For context, $\mathrm{q}_{\text {sat }}$ can vary by a few $\mathrm{g} / \mathrm{kg}, 10^{\circ}$ either side of the East Pacific ITCZ during Aug-Oct, and anomalies during ENSO events have a similar magnitude.

\section{High sensitivity of precipitation to SST}

We hypothesised above $\left(\mathrm{H}_{0}\right)$ that $\mathrm{k}_{\mathrm{qsat}}$ may be too low in most models. To begin testing this, the results in Figure 2a-f are replotted, but with the 'high- $\mathrm{k}_{\mathrm{qsat}}$ ' subset of models highlighted in magenta (Figure $2 \mathrm{~g}-1$ ). The 'high- $\mathrm{k}_{\mathrm{qsat}}$ ' subset shows much better agreement with TRMM than the full ensemble, in all six panels. Conversely, the 'low- $\mathrm{k}_{\mathrm{qsat}}$ ' subset performs much worse

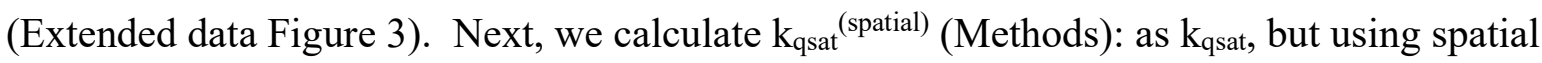
patterns in climate means, rather than internal variability (Figure 4b). Again, models closest to the observations (Figure $4 \mathrm{~b}$, horizontal line) tend to be those with high $\mathrm{k}_{\mathrm{qsat}}$. These results all imply that $\mathrm{k}_{\mathrm{qsat}}$ should be high in the real world $\left(\mathrm{H}_{0}\right)$.

These results also show that $\mathrm{k}_{\mathrm{qsat}}$ is relevant to both spatial and temporal variations in precipitation. We emphasise this by quantifying the overall sensitivity of precipitation to local SST $\left(k_{q s a t}^{\text {spattemp }}\right)$, including both spatial and temporal variations (including spatial variation in $\mathrm{P}_{0}$, Methods). $k_{q s a t}^{\text {spattemp }}$ is well correlated with $\mathrm{k}_{\mathrm{qsat}}$ (Extended data Figure 2i). This confirms that $\mathrm{k}_{\mathrm{qsat}}$ is a useful measure of the underlying sensitivity of precipitation to local SST, relevant to spatial and temporal variations. $\mathrm{k}_{\mathrm{qsat}}$ does not give information about tropical mean precipitation, which is governed by different processes ${ }^{31}$. $\mathrm{k}_{\mathrm{qsat}}$ remains our primary measure of precipitation sensitivity to local SST, because it is insensitive to details of SST patterns. In contrast, $k_{\text {qsat }}^{\text {spattemp }}$ and $\mathrm{k}_{\mathrm{qsat}}{ }^{\text {(spatial) }}$ may be sensitive to the specific spatial 
patterns in climatological SST (Methods), explaining some of the noise in Figure 4b and Extended data Figure 2i.

We estimate a lower bound for $\mathrm{k}_{\mathrm{qsat}}$, using observed interannual variability (independent of Figure 2; Methods). Three values of $\mathrm{k}_{\mathrm{qsat}}$ are estimated, exactly as for the models, but using TRMM precipitation, and $\mathrm{q}_{\text {sat }}$ from each of three different SST datasets (HadISST ${ }^{32}$ version 1.1, $\mathrm{ERSST}^{33}$ version 4 and $\mathrm{COBE}^{34}$ version 2). Uncertainties are estimated, from SST error (including regression dilution bias) and internal variability (the TRMM observational period only partly overlaps the model simulation period). A lower observational bound (95\% confidence) of $0.51 \mathrm{~kg} / \mathrm{g}$ for $\mathrm{k}_{\mathrm{qsat}}$ is obtained.

For a central observational estimate of $\mathrm{k}_{\mathrm{qsat}}$ (details in Methods), we return to Figure 2. We ask: if all CMIP5 models had the same value of $\mathrm{k}_{\mathrm{qsat}}$, with what value would they best reproduce the observations in Figure 2? We first find where, geographically, the models are most sensitive to $\mathrm{k}_{\mathrm{qsat}}$. This reveals seven intervals (shaded in Figure $2 \mathrm{~g}-1$ ). For each interval, model errors relative to TRMM are regressed against modelled $\mathrm{k}_{\mathrm{qsat}}$ (Extended data Figure 6). For each interval, $\mathrm{k}_{\mathrm{qsat}}$ is estimated as where the regression line intercepts the $\mathrm{x}$-axis (the value for a theoretical model with zero precipitation error). These seven estimates of $\mathrm{k}_{\mathrm{qsat}}$ range from 0.56 to $0.68 \mathrm{~kg} / \mathrm{g}$ (Figure $4 \mathrm{a}$, white dashed lines), all larger than our lower bound estimate. The spread of estimates comes from uncertainty in processes not quantified by $\mathrm{k}_{\mathrm{qsat}}$. The range of conditions used, covering spatial, seasonal and temporal variability across different locations, helps to quantify and mitigate this uncertainty. Robustness is tested by plotting results from the sixth model intercomparison project (CMIP6, not used to select the seven intervals) on Extended data Figure 6. The mean of the seven $\mathrm{k}_{\mathrm{qsat}}$ values $(0.6 \mathrm{~kg} / \mathrm{g}$; or, 
using Equation 4, 80\% per $\mathrm{g} / \mathrm{kg}$ ) is our central estimate (for 1980-2005; other periods would give slightly different values, from internal SST variability - Extended data Figure $2 \mathrm{~h}$ ).

These results, from two independent methods, suggest that most models underestimate $\mathrm{k}_{\mathrm{qsat}}$. Our central estimate $(0.6 \mathrm{~kg} / \mathrm{g}$, Figure $4 \mathrm{a}$, horizontal black line; Figure $4 \mathrm{~b}$, vertical line $)$ is greater than 43 of the 47 model values from CMIP5 and CMIP6. This implies that models underestimating the sensitivity of precipitation to local SST underlies a range of model biases over tropical oceans. CMIP5 and CMIP6 have similar ranges of $\mathrm{k}_{\mathrm{qsat}}$ values (Figure 4a), highlighting the need for accelerated model development.

Other studies ${ }^{35}$ have found biases in a different aspect of the SST-precipitation relationship: model precipitation often tracks SST maxima more closely than in observations. We quantify this in each CMIP5 model as the correlation coefficient between climatological spatial patterns of precipitation and SST, for each season, then average the four seasonal values. This 'spatial-correlation index' is uncorrelated with $\mathrm{k}_{\mathrm{qsat}}(\mathrm{r}=0.01$; i.e. models with a high spatial-correlation index can have high, low or intermediate $\mathrm{k}_{\mathrm{q} s a t}$ ), so it involves different processes.

\section{Processes behind uncertainty in kqsat}

To guide model improvements, we explore what causes model differences in $\mathrm{k}_{\mathrm{qsat}}$, revealing links to shallow atmospheric circulations. We first note that $\mathrm{k}_{\mathrm{qsat}}$ involves processes unrelated to tropical mean precipitation: the correlation across CMIP5 models between the 
two measures is 0.03 . Energy budgets constrain tropical mean precipitation ${ }^{31}$, while the value of $\mathrm{k}_{\mathrm{qsat}}$ affects precipitation variation in both time and space.

229 Beginning with interannual variability, we define $\mathrm{k}_{\mathrm{qsat}}{ }^{\text {wap }}(\mathrm{p})$ : the sensitivity of the vertical pressure velocity (wap) to local SST change, at each pressure level (p). This is evaluated like $\mathrm{k}_{\mathrm{qsat}}$, using data from all seasons across the tropical oceans, but using wap(p) instead of $\log$ (precipitation). A deep mode dominates tropical variability ${ }^{36}$, so the CMIP5 mean profile of $\mathrm{k}_{\mathrm{qsat}}{ }^{\text {wap }}$ peaks around $450 \mathrm{hPa}$ (Figure 5a). In contrast, model spread in $\mathrm{k}_{\mathrm{qsat}}$ is linked to shallow circulations: correlations between $\mathrm{k}_{\mathrm{qsat}}{ }^{\text {wap }}(\mathrm{p})$ and $\mathrm{k}_{\mathrm{qsat}}$ (Figure $\left.5 \mathrm{~b}\right)$ peak near $700 \mathrm{hPa}(\mathrm{r}$ $=-0.9$; correlations are small at $1000 \mathrm{hPa}$, as wap approaches zero near the surface). That is, in models with high $\mathrm{k}_{\mathrm{qsat}}$ (as in the real world), shallow circulations respond strongly to SST anomalies. Although deep circulations are important ${ }^{36}$ in all models, and shallow circulations have been linked to mean precipitation, especially over the Eastern Pacific ${ }^{7}$, our novel finding is that shallow circulations are central to model uncertainty in SST-driven precipitation variability, across the tropics.

Shallow circulations are further linked to model differences in climate means. We study zonal, ocean-only means over 180W-10E (most of the Pacific, entire Atlantic), in Aug-Oct, when meridional SST gradients are strong. CMIP5 results are used to define key regions (black and orange lines in Figure 5c-e), and CMIP6 used to test the conclusions. As expected $^{4,7}$, CMIP5 mean vertical velocity profiles are bottom heavy, but extend throughout the troposphere (Figure 5c, colours). Meridional wind (white contours) peaks near the tropopause, with a weaker shallow flow between $500-700 \mathrm{hPa}^{37}$. Again, however, inter-model spread in $\mathrm{k}_{\mathrm{qsat}}$ is associated with shallow circulations: models with high $\mathrm{k}_{\mathrm{qsat}}$ have stronger 

ascent in the ITCZ (Figure 5d, blue region; Extended Data Figure 8c, magenta line), stronger trade winds and stronger return flow between 500-700hPa (Figure 5d, white contours; Extended Data Figure $8 \mathrm{~b}$, magenta line). This shallow circulation is weak in the low- $\mathrm{k}_{\mathrm{qsat}}$ mean (Extended Data Figure 8a-c, blue lines).

The weak link between model differences in $\mathrm{k}_{\mathrm{qsat}}$ and deep circulations may arise partly from physical constraints. In descending air, differences in vertical velocity are largest below about $600 \mathrm{hPa}$ (Extended Data Figure 8a,i). This is partly explained by the verticallyintegrated dry static energy (DSE) budget. This budget constrains vertical velocities, requiring balance between radiative, sensible and latent heating, and advection of DSE (Methods). In descending air above $600 \mathrm{hPa}$, there are fewer uncertain processes affecting this budget, with negligible energy input from cloud and precipitation. Here, therefore, downward advection of DSE is balanced mostly by dry clear-sky radiative cooling (Extended Data Table 1). Further, vertical temperature profiles are similar across CMIP5 models. This constrains both radiative cooling and vertical gradients of DSE, limiting model differences in vertical velocity. Model temperatures are constrained, near the surface by SST, and near the tropopause as modelling groups aim to reproduce observed outgoing longwave radiation. Below $600 \mathrm{hPa}$, there are additional sources of uncertainty, from cloud and precipitation $^{38}$, leading to larger model differences in shallow descent, and so stronger links to differences in $\mathrm{k}_{\mathrm{qsat}}$. 
273 The depth of the meridional return flow (500-700hPa, Figure 5e, white contours) suggests a

274 circulation driven by precipitating shallow convection ${ }^{37,39}$. The alternative, sea-breeze

275 mechanism reaches lower levels ${ }^{37}$. Both circulation types may exist over the Galapagos

276 (Extended Data Figure 8g): here, model meridional winds between 600-700hPa (shallow-

277 convection-type) are uncorrelated with those between 700-850hPa (sea-breeze-type),

278 indicating different physical processes at these two levels. The column dry static energy

279 budget (Methods) also implicates precipitating shallow convection. Model differences in this

280 budget are predominantly a balance between vertical advection integrated over 600-1000 hPa,

281 and precipitation latent heating (Extended Data Table 1, final column): in descending air

282 below $600 \mathrm{hPa}$, high- $\mathrm{k}_{\mathrm{qsat}}$ models have stronger shallow advective warming from stronger

283 shallow descent, balancing weaker warming from weaker precipitation. As expected, the

284 ensemble mean in descending air is mostly a balance between radiative cooling and advective

285 warming.

Causality is hard to fully establish, but the most likely explanation of our results is that model differences in $\mathrm{k}_{\mathrm{qsat}}$ mostly originate from model differences in the behaviour of shallow precipitating convection. Such differences would affect the sensitivity of precipitation to SST directly. The consequent differences in shallow latent heating also appear to lead to differences in shallow circulations. This couples shallow vertical velocities in descending and ascending air (Extended Data Figure 8e), further modifying the sensitivity of precipitation to SST. coupling to circulation ${ }^{5,42}$, are well established. Improvements in $\mathrm{k}_{\mathrm{qsat}}$ in the CNRM model 
from CMIP5 $(0.43 \mathrm{~kg} / \mathrm{g})$ to CMIP6 $(0.54 \mathrm{~kg} / \mathrm{g})$ are largely associated with convection scheme changes. Running CNRM-CM6 with the CNRM-CM5 convection scheme gives $\mathrm{k}_{\mathrm{qsat}}=0.36$ $\mathrm{kg} / \mathrm{g}$, even smaller than that of CNRM-CM5. That is, the effect of changing the convection scheme is partly offset by changes in other schemes. Changes from CM5 to CM6 include the shallow convection scheme and the transition from shallow to deep convection ${ }^{43}$. These, and other physics schemes, including boundary layer, deep or mid-level convection, or microphysics, could all affect how shallow precipitating convection responds to SST.

Other processes may have smaller contributions. Dry shallow circulations ${ }^{44}$ are more important over hot, dry land. A limited role for differences in radiation (Extended Data Table 1, final column), suggests cloud parameterizations are not dominant. Differences in dynamical schemes are thought to be less likely to be important for tropical precipitation biases, although coupling of dynamics to physics is important ${ }^{45-47}$.

Models with stronger shallow circulations can also import more moist static energy in ascending air, driving enhanced deep convection ${ }^{48}$. Our results support this (Extended Data Figure $8 \mathrm{~h}$ ), showing that model differences in shallow ascent are strongly positively correlated with differences in deep ascent. This is an indirect link to $\mathrm{k}_{\mathrm{qsat}}$, which is more weakly associated with deep ascent rates (Figure 5d).

\section{Strong real-world shallow circulations}

Shallow circulations are challenging to observe ${ }^{11}$, but our results suggest they are stronger in the real world than in most models. Models with high $\mathrm{k}_{\mathrm{qsat}}$ (as in the real world) tend to have 
strong shallow circulations (in both climate means and internal variability). We test this further with two independent observations, in Aug-Oct. In models, there is a strong $(\mathrm{r}=0.86)$ relationship between shallow descent, and northward trade winds (Figure 4c). If the shallow descent is strong in the real world, we would expect strong northward trades - and this is confirmed by QuikSCAT satellite observations ${ }^{49}$ (SeaWinds scatterometer, Level 3 product, years 1999-2009 - horizontal line in Figure 4c). There is, similarly, a strong $(\mathrm{r}=0.81)$ relationship (Figure 4d) between 500-700hPa meridional winds over our study region, and the mean 600-700hPa meridional wind over Galapagos and Christmas Islands (915 MHZ wind profiler ${ }^{8,50}$ observation sites, years 1994-2005 at Galapagos, 1990-2002 at Christmas Island; few observations reach above $600 \mathrm{hPa}$ ). If the large-scale $500-700 \mathrm{hPa}$ wind is strong in the real world, we would expect strong southward winds in the observations, and this is what the wind profilers show (horizontal line in Figure 4d). These results, using multiple observations, confirm a previous suggestion based on a single reanalysis product ${ }^{5}$.

\section{Conclusions}

Our results show that $\mathrm{k}_{\mathrm{qsat}}$ is linked to a range of model biases in precipitation and atmospheric circulation. Improving $\mathrm{k}_{\mathrm{qsat}}$ should reduce those biases, giving greater confidence in seasonal through multi-decadal model projections. $\mathrm{k}_{\mathrm{qsat}}$ affects the strength of precipitation variation in both time and space. Other biases, in large-scale energy budgets, and teleconnections, also affect precipitation. We show that $\mathrm{k}_{\mathrm{qsat}}$ can be constrained by observations, and give evidence that improving the representation of shallow tropical precipitating convection, and its coupling to SST and circulation, could improve $\mathrm{k}_{\mathrm{qsat}}$. This identifies specific model development goals and gives new ways of linking these to observable physical processes. 
1. Philander, S. G. H. El-Nino Southern Oscillation Phenomena. Nature 302, 295-301 (1983).

2. Pierrehumbert, R. T. Thermostats, Radiator Fins, and the Local Runaway Greenhouse. J. Atmos. Sci. 52, 1784-1806 (1995).

3. Tian, B. J. Spread of model climate sensitivity linked to double-Intertropical Convergence

4. Back, L. E. \& Bretherton, C. S. Geographic variability in the export of moist static energy and

5. Sherwood, S. C., Bony, S. \& Dufresne, J. L. Spread in model climate sensitivity traced to atmospheric convective mixing. Nature 505, 37-+ (2014).

6. Trenberth, K. E., Stepaniak, D. P. \& Caron, J. M. The global monsoon as seen through the divergent atmospheric circulation. J. Clim. 13, 3969-3993 (2000).

7. Back, L. E. \& Bretherton, C. S. A Simple Model of Climatological Rainfall and Vertical Motion

8. Zhang, C. D., Nolan, D. S., Thorncroft, C. D. \& Nguyen, H. Shallow meridional circulations in Patterns over the Tropical Oceans. J. Clim. 22, 6477-6497 (2009).

the tropical atmosphere. J. Clim. 21, 3453-3470 (2008).

9. $\quad \mathrm{Li}, \mathrm{R}$. \& Fu, Y. F. Tropical precipitation estimated by GPCP and TRMM PR observations. Adv. Atmos. Sci. 22, 852-864 (2005).

10. Prakash, S., Mahesh, C. \& Gairola, R. M. Comparison of TRMM Multi-satellite Precipitation Analysis (TMPA)-3B43 version 6 and 7 products with rain gauge data from ocean buoys. Remote Sens. Lett. 4, 677-685 (2013).

11. Bellon, G., Reitebuch, O. \& Naumann, A. K. Shallow Circulations: Relevance and Strategies for Satellite Observation. Surv. Geophys. 38, 1509-1528 (2017).

12. Li, G. \& Xie, S. P. Tropical Biases in CMIP5 Multimodel Ensemble: The Excessive Equatorial Pacific Cold Tongue and Double ITCZ Problems. J. Clim. 27, 1765-1780 (2014).

13. Xie, S. P. et al. Towards predictive understanding of regional climate change. Nat. Clim. Chang. 5, 921-930 (2015).

14. Byrne, M. P. \& Schneider, T. Energetic Constraints on the Width of the Intertropical Convergence Zone. J. Clim. 29, 4709-4721 (2016).

15. Bellenger, H., Guilyardi, E., Leloup, J., Lengaigne, M. \& Vialard, J. ENSO representation in climate models: from CMIP3 to CMIP5. Clim. Dyn. 42, 1999-2018 (2014).

16. Zhang, X. X., Liu, H. L. \& Zhang, M. H. Double ITCZ in Coupled Ocean-Atmosphere Models: From CMIP3 to CMIP5. Geophys. Res. Lett. 42, 8651-8659 (2015).

17. Hirota, N. \& Takayabu, Y. N. Reproducibility of precipitation distribution over the tropical oceans in CMIP5 multi-climate models compared to CMIP3. Clim. Dyn. 41, 2909-2920 (2013).

18. Dixit, V., Geoffroy, O. \& Sherwood, S. C. Control of ITCZ Width by Low-Level Radiative Heating From Upper-Level Clouds in Aquaplanet Simulations. Geophys. Res. Lett. 45, 5788-5797. https://doi.org/10.1029/2018GL078292 (2018). 
19. He, J. et al. Precipitation Sensitivity to Local Variations in Tropical Sea Surface Temperature. J. Clim. 31, 9225-9238 (2018).

20. Rushley, S. S., Kim, D., Bretherton, C. S. \& Ahn, M. S. Reexamining the Nonlinear MoisturePrecipitation Relationship Over the Tropical Oceans. Geophys. Res. Lett. 45, 1133-1140 (2018).

21. Bretherton, C. S., Peters, M. E. \& Back, L. E. Relationships between water vapor path and precipitation over the tropical oceans. J. Clim. 17, 1517-1528 (2004).

22. Kanemaru, K. \& Masunaga, H. A Satellite Study of the Relationship between Sea Surface Temperature and Column Water Vapor over Tropical and Subtropical Oceans. J. Clim. 26, 4204-4218 (2013).

23. TRMM. Tropical Rainfall Measuring Mission, TRMM (TMPA/3B43) Rainfall Estimate L3 1 month 0.25 degree $\times 0.25$ degree V7, Greenbelt, MD, Goddard Earth Sciences Data and Information Services Center (GES DISC), Accessed 2017. 10.5067/TRMM/TMPA/MONTH/7 (2011).

24. Huffman, G. J. et al. The TRMM multisatellite precipitation analysis (TMPA): Quasi-global, multiyear, combined-sensor precipitation estimates at fine scales. J. Hydrometeorol. 8, 38-55 (2007).

25. Adler, R. F. et al. The Global Precipitation Climatology Project (GPCP) Monthly Analysis (New Version 2.3) and a Review of 2017 Global Precipitation. Atmosphere (Basel). 9, (2018).

26. McPhaden, M. J. et al. The tropical ocean global atmosphere observing system: A decade of progress. J. Geophys. Res. 103, 14169-14240 (1998).

27. McPhaden, M. J. et al. RAMA The Research Moored Array for African-Asian-Australian Monsoon Analysis and Prediction. Bull. Am. Meteorol. Soc. 90, 459-+ (2009).

28. Bourles, B. et al. The PIRATA program: History, accomplishments, and future directions. Bull. Am. Meteorol. Soc. 89, 1111-+ (2008).

29. Serra, Y. L., A'Hearn, P., Freitag, H. P. \& McPhaden, M. J. ATLAS self-siphoning rain gauge error estimates. J. Atmos. Ocean. Technol. 18, 1989-2002 (2001).

30. Taylor, K. E., Williamson, D. \& Zwiers, F. W. The sea surface temperature and sea-ice concentration boundary conditions for AMIP II simulations. PCMDI Rep. No. 60, Progr. Clim. Model Diagnosis Intercomparison, Lawrence Livermore Natl. Lab. Livermore, California, 25 pp (2000).

31. Allen, M. R. \& Ingram, W. J. Constraints on future changes in climate and the hydrologic cycle. Nature 419, 224-+ (2002).

32. Rayner, N. A. et al. Global analyses of sea surface temperature, sea ice, and night marine air temperature since the late nineteenth century. J. Geophys. Res. 108, (2003).

33. Huang, B. Y. et al. Extended Reconstructed Sea Surface Temperature Version 4 (ERSST.v4). Part I: Upgrades and Intercomparisons. J. Clim. 28, 911-930 (2015).

34. Hirahara, S., Ishii, M. \& Fukuda, Y. Centennial-Scale Sea Surface Temperature Analysis and Its Uncertainty. J. Clim. 27, 57-75 (2014).

35. Biasutti, M., Sobel, A. H. \& Kushnir, Y. AGCM precipitation biases in the tropical Atlantic. J. 
Clim. 19, 935-958 (2006).

36. Holloway, C. E. \& Neelin, J. D. The convective cold top and quasi equilibrium. J. Atmos. Sci. (2007) doi:10.1175/JAS3907.1.

37. Nolan, D. S., Powell, S. W., Zhang, C. D. \& Mapes, B. E. Idealized Simulations of the Intertropical Convergence Zone and Its Multilevel Flows. J. Atmos. Sci. 67, 4028-4053 (2010).

38. Knutson, T. R. \& Manabe, S. Time-mean response over the tropical Pacific to increased CO2 in a coupled ocean-atmosphere model. J. Clim. (1995) doi:10.1175/15200442(1995)008<2181:TMROTT>2.0.CO;2.

39. Wu, Z. H. A shallow CISK, deep equilibrium mechanism for the interaction between largescale convection and large-scale circulations in the tropics. J. Atmos. Sci. 60, 377-392 (2003).

40. Lin, Y. et al. TWP-ICE global atmospheric model intercomparison: Convection responsiveness and resolution impact. J. Geophys. Res. Atmos. (2012) doi:10.1029/2011JD017018.

41. Randall, D. A. Beyond deadlock. Geophys. Res. Lett. (2013) doi:10.1002/2013GL057998.

42. Bony, S. \& Dufresne, J. L. Marine boundary layer clouds at the heart of tropical cloud feedback uncertainties in climate models. Geophys. Res. Lett. (2005) doi:10.1029/2005GL023851.

43. Voldoire, A. et al. Evaluation of CMIP6 DECK Experiments With CNRM-CM6-1. J. Adv. Model. Earth Syst. (2019) doi:10.1029/2019MS001683.

44. Nie, J., Boos, W. R. \& Kuang, Z. Observational evaluation of a convective quasi-equilibrium view of monsoons. J. Clim. (2010) doi:10.1175/2010JCLI3505.1.

45. Stevens, B. \& Bony, S. What are climate models missing? Science (2013) doi:10.1126/science.1237554.

46. Oueslati, B. \& Bellon, G. Convective Entrainment and Large-Scale Organization of Tropical Precipitation: Sensitivity of the CNRM-CM5 Hierarchy of Models. J. Clim. 26, 2931-2946 (2013).

47. Vial, J., Bony, S., Stevens, B. \& Vogel, R. Mechanisms and Model Diversity of Trade-Wind Shallow Cumulus Cloud Feedbacks: A Review. Surveys in Geophysics (2017) doi:10.1007/s10712-017-9418-2.

48. Fläschner, D., Mauritsen, T., Stevens, B. \& Bony, S. The signature of shallow circulations, not cloud radiative effects, in the spatial distribution of tropical precipitation. J. Clim. (2018) doi:10.1175/JCLI-D-18-0230.1.

49. NASA. SeaWinds on QuikSCAT Level 3 Surface Northward Wind for Climate Model Co mparison. Ver. 1. PO.DAAC, CA, USA. Dataset accessed [2019-09-06] at https://doi.org/10.5067/QS SNW-CMIP1. (2012).

50. Gage, K. S., Williams, C. R. \& Ecklund, W. L. UHF wind profilers: a new tool for diagnosing tropical convective cloud systems. Bull. - Am. Meteorol. Soc. (1994) doi:10.1175/15200477(1994)075<2289:UWPANT>2.0.CO;2. 

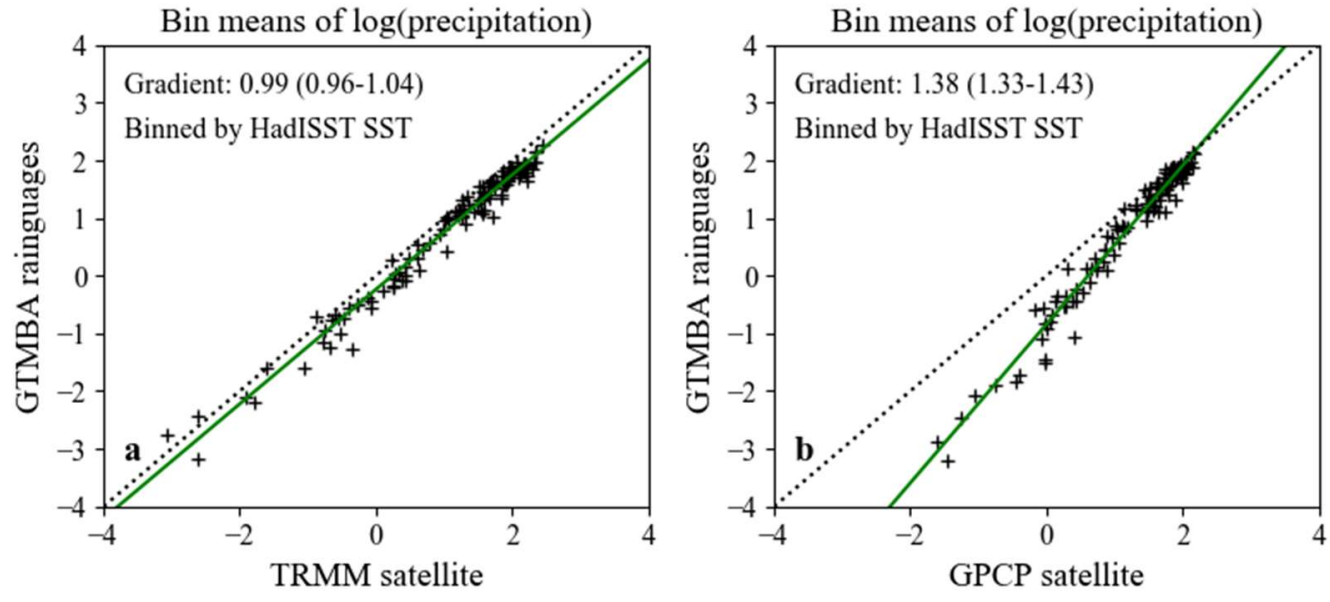

463

464 Validating observations of $\log$ precipitation from satellites. GTMBA in-situ raingauge

465 observations versus satellite observations from a TRMM and b GPCP. Each symbol

466 represents the mean of all seasonal mean data within a given SST bin (Methods). Green line:

467 best fit line (gradient and its 95\% confidence interval quoted in each figure); dotted line: 1:1 468 line. 

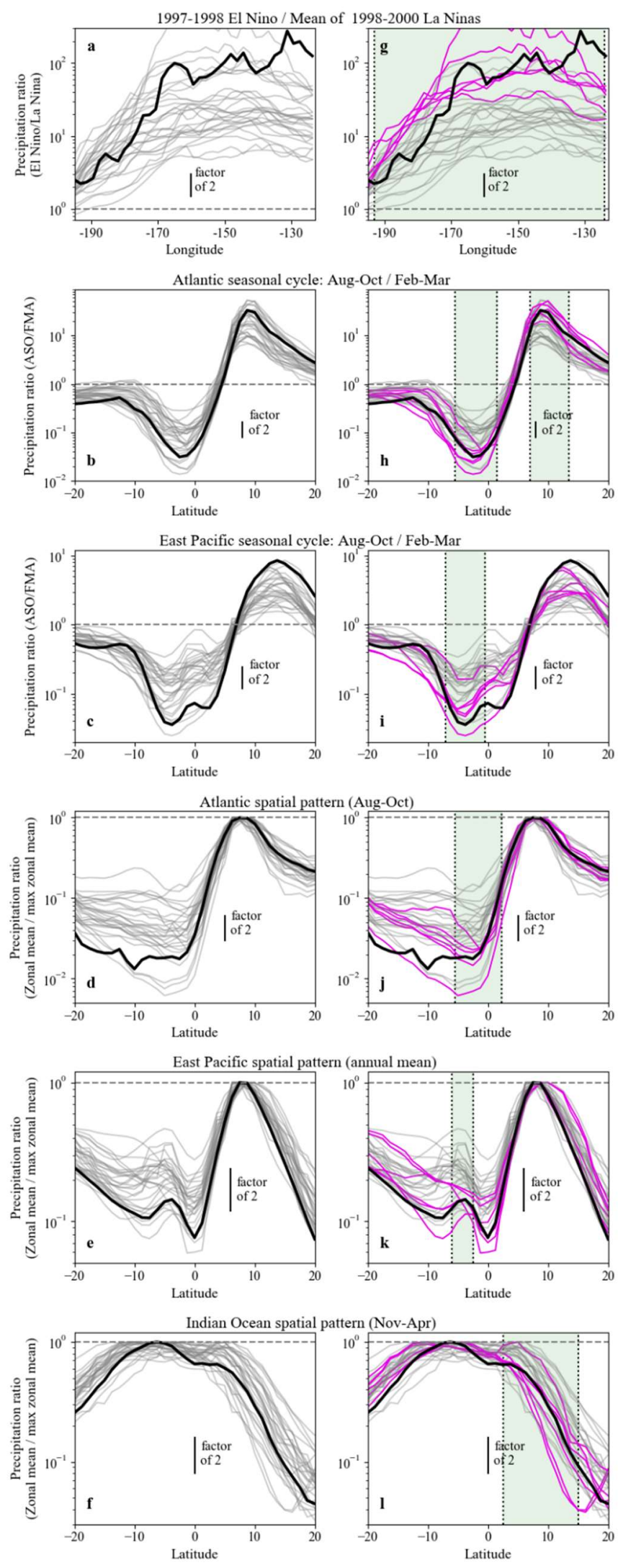

472 Figure 2. Model precipitation biases. (black) TRMM observations. Horizontal dashed line 473 marks precipitation ratio=1. a-f all CMIP5 models are shown in grey lines; $\mathbf{g - i}$ magenta: 
474 'high- $\mathrm{k}_{\mathrm{qsat}}$ ' subset; grey: other models. Spatial patterns (bottom 3 rows) given by scaling

475 zonal mean precipitation by its latitudinal maximum. Green shading marks the intervals used

476 for the 7 estimates of $\mathrm{k}_{\mathrm{qsat}}$. These examples were chosen as they feature large

477 differences/gradients in SST. Precipitation ratios are plotted because of the form of Equation $478 \quad 1$.

479

480 

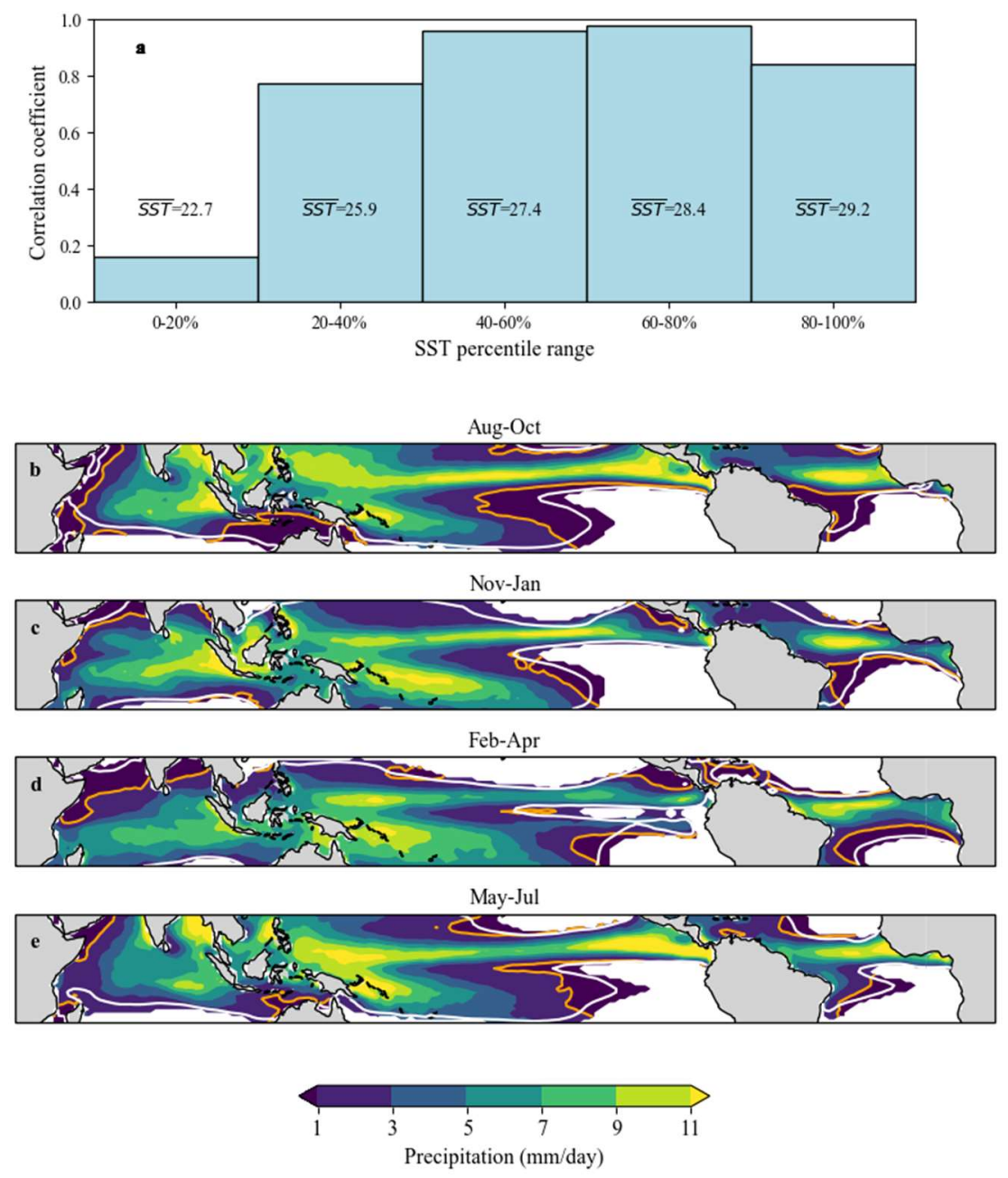

Figure 3. The region of

applicability of kqsat. (a) each bar represents a climatological zone covering $20 \%$ of the

tropical oceans, defined by the seasonal climatological SSTs (e.g. the left bar is the zone with the coolest $20 \%$ of SSTs - white masked ocean in the maps below). Climatological zones are defined separately for each season. Bar height: the correlation coefficient, across CMIP5 models, between the standard calculation of kqsat, and that calculated only over the selected climatological zone. Mean SST $\left({ }^{\circ} \mathrm{C}\right)$ for each zone is also shown. (b-e) Colours: mean TRMM precipitation; orange line highlights $1 \mathrm{~mm} /$ day contour. Data is masked over the $20 \%$ of the oceans where kqsat is inapplicable (left-hand bar in panel a shows low correlation). White contour shows the $30^{\text {th }}$ percentile of SST: the standard calculation of kqsat uses data inside this contour. 

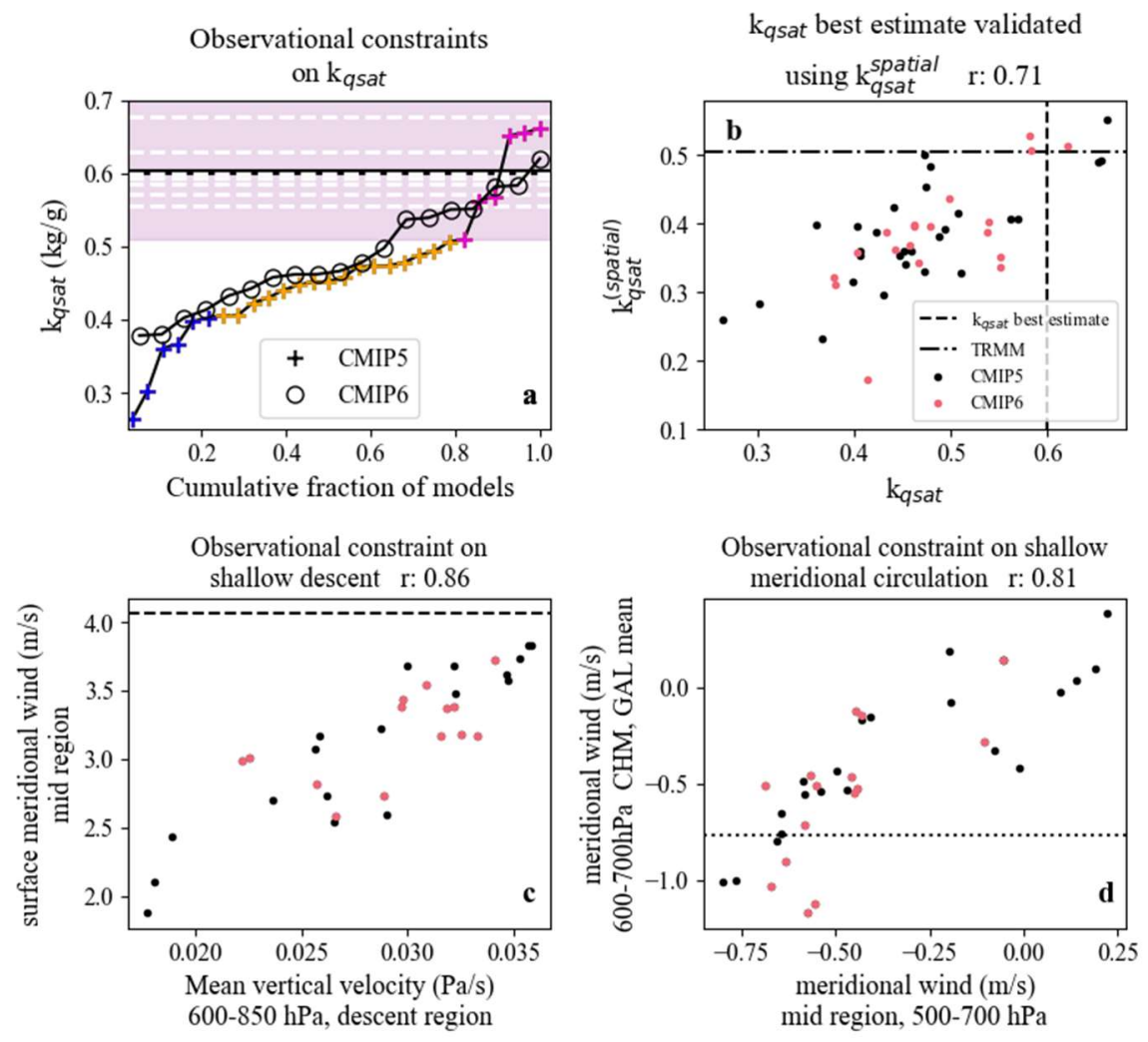

Figure 4. High sensitivity of precipitation to SST, and strong shallow circulations, in the real world. a horizontal lines mark (white dashes) the 7 estimates of $\mathrm{k}_{\mathrm{qsat}}$ (Extended data Figure 6), and the central estimate (black solid); shading marks $\mathrm{k}_{\mathrm{qsat}}$ values above our lower-bound estimate; symbols mark sorted model $\mathrm{k}_{\mathrm{qsat}}$ values for (crosses) CMIP5 (blue and magenta denote low- $\mathrm{k}_{\mathrm{qsat}}$ and high- $\mathrm{k}_{\mathrm{qsat}}$ model subsets) and (circles) CMIP6. b $\mathrm{k}_{\mathrm{qsat}}{ }^{\text {(spatial) }}$ versus $\mathrm{k}_{\mathrm{qsat}}$, for each (black) CMIP5 and (red) CMIP6 model; horizontal line: $\mathrm{k}_{\mathrm{qsat}}{ }^{\text {(spatial) }}$ from TRMM observations; vertical line: best estimate of $\mathrm{k}_{\mathrm{qsat}} \mathbf{c}, \mathbf{d}$ each symbol represents one CMIP5 (black) or CMIP6 (red) model; title gives Pearson correlation coefficient. c surface meridional wind averaged over the mid-region $(180 \mathrm{~W}-10 \mathrm{E}, 1-7 \mathrm{~N})$ versus shallow descent index (defined in Figure 5); horizontal line marks QuikSCAT observation. d meridional wind averaged over Galapagos \& Christmas island, 600-700hPa (few observations above $600 \mathrm{hPa}$ ) versus meridional wind averaged over the mid region $(180 \mathrm{~W}-10 \mathrm{E}, 1-7 \mathrm{~N}), 500-700 \mathrm{hPa}$; horizontal line marks wind profiler observation. 

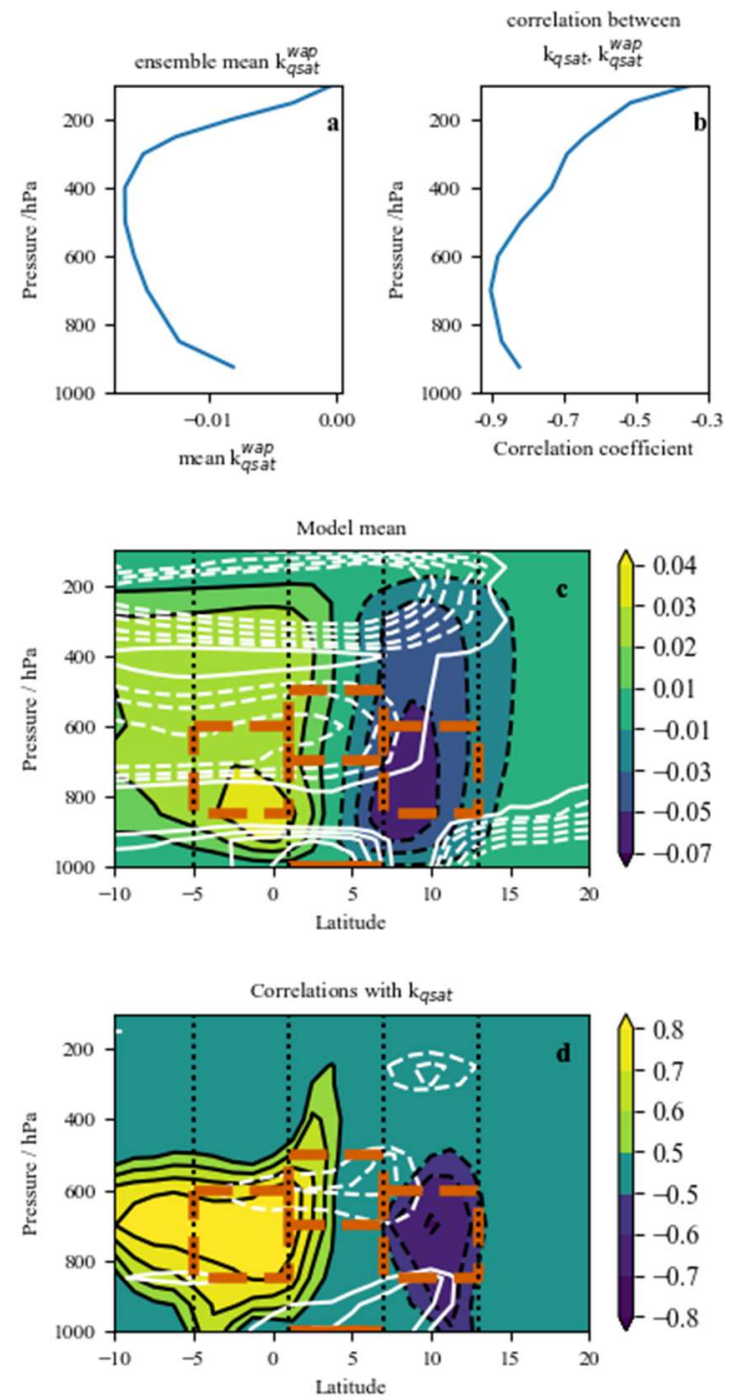

507

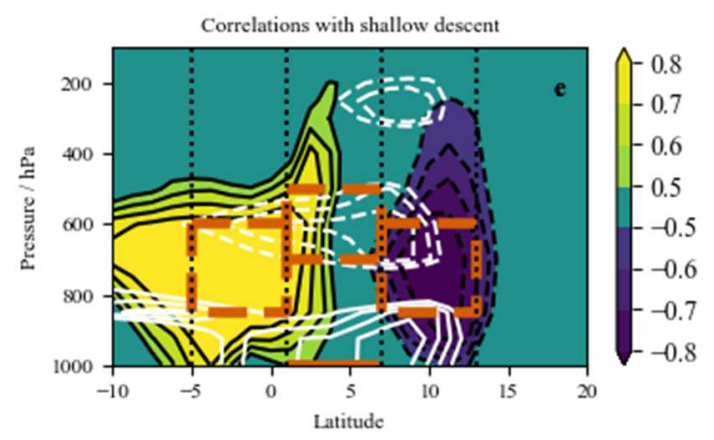

508 Figure 5. Linking $\mathrm{k}_{\mathrm{qsat}}$ to shallow circulations. a,b quantifies internal variability, and $\mathbf{c}-\mathbf{e}$

509 climate means. a CMIP5 ensemble mean of $\mathrm{k}_{\mathrm{qsat}}{ }^{\text {wap }}(\mathrm{Pa} \mathrm{kg} / \mathrm{g})$, at each pressure level. $\mathbf{b}$ inter-

510 model correlations (Pearson $\mathrm{r}$ ) between $\mathrm{k}_{\mathrm{qsat}}$, and $\mathrm{k}_{\mathrm{qsat}}{ }^{\text {wap }}$, at each pressure level. Correlations

511 are negative because of the definition of wap. c-e Aug-Oct, 180W-10E zonal means. c

512 CMIP5 ensemble mean of (colours) vertical velocity $(\mathrm{Pa} / \mathrm{s})$ and (white contours) meridional 
513 wind. $\mathbf{d}$ inter-model correlations between $\mathrm{k}_{\mathrm{qsat}}$ and mean vertical velocity (colours) and

514 between $\mathrm{k}_{\mathrm{qsat}}$ and mean meridional wind (white contours). e as $\mathbf{d}$, but for correlations with

515 the shallow descent index instead of $\mathrm{k}_{\mathrm{qsat}}$ (shallow descent index $=$ vertical velocity averaged

516 over left-hand orange-dashed box: 5S-1N, 850-600 hPa).

517

518 
524 Results are based on seasonal means of precipitation and SST, over the tropical oceans (20S-

$52520 \mathrm{~N}) . \mathrm{q}_{\text {sat }}$ is calculated as the saturation specific humidity at the seasonal mean sea-surface

526 temperature and $1000 \mathrm{hPa}$ air pressure. Use of seasonal mean SST here means that $\mathrm{q}_{\text {sat }}$ will

527 be lower than the seasonal mean of saturation specific humidity calculated from daily SST

528 (due to sub-seasonal SST variability, and nonlinearity in the humidity calculation). We use

529 seasonal mean SST to minimise observational error: sub-seasonal SST variability is hard to 530 observe accurately.

\section{Observations}

532 Satellite precipitation data are seasonal averages of monthly means from V7 of the 3B43

533 Tropical Rainfall Measuring Mission (TRMM) ${ }^{23,24}$ dataset, covering 1998-2015. Data from

534 V2.3 of the Global Precipitation Climatology Project $\left(\mathrm{GPCP}^{25}\right)$ retrieval are included in

535 Figure 1 only.

536 In-situ raingauge data from 89 buoys of the Global Tropical Moored Buoy Array (all buoys

537 with more than 1 year of precipitation data), from the Tropical Ocean-Global Atmosphere

$538\left(\right.$ TOGA $\left.^{26}\right)$ observing system, the Prediction and Research Moored Array in the Atlantic

539 PIRATA $^{28}$ ) and the Research Moored Array for African-Asian-Australian Monsoon

540 Analysis and Prediction $\left(\mathrm{RAMA}^{27}\right)$, were retrieved as daily means. Days with lower quality

541 data (quality codes not equal to 1 or 2) were rejected. Monthly means were then calculated

542 only for months with 20 or more days with code 1 or 2 data (other months are marked as 
missing). Seasonal means were taken only where three consecutive months had non-missing data.

Monthly mean SSTs are taken from four different datasets. The CMIP5 AMIP dataset ${ }^{30}$ (the dataset used to drive the AMIP SST-forced model runs) is available only for 1980-2005.

547

This was used to calculate $\mathrm{k}_{\mathrm{qsat}}$ for each model. For our observational estimate of a lower bound on $\mathrm{k}_{\mathrm{qsat}}$ (using TRMM precipitation), three SST datasets were used: HadISST $^{32}$ version 1.1, ERSST $^{33}$ version 4 and $\mathrm{COBE}^{34}$ version 2 (the AMIP dataset used by the model simulations was not used, due to its limited temporal overlap with the TRMM operational period).

Surface meridional wind observations are from SeaWinds on QuikSCAT Level 3, for the period Aug 1999-Oct 2009. Wind profiler observations at San Cristóbal, Galápagos $\left(0.9^{\circ} \mathrm{S}\right.$, 89. $\left.7^{\circ} \mathrm{W}, 1994-2005\right)$ and Christmas Island $\left(2.8^{\circ} \mathrm{N}, 157.5^{\circ} \mathrm{W}, 1990-2002\right)$ used $915 \mathrm{MHz}$ in low mode, as used in other studies of shallow circulation ${ }^{8}$.

\section{Model data}

557 All model results are from atmosphere-only AMIP runs (one run per model version) forced by observed SST, corresponding to the period 1980-2005. This includes 28 models from CMIP5 (ACCESS1-0, ACCESS1-3, BNU-ESM, CCSM4, CESM1-CAM5, CNRM-CM5, CSIRO-Mk3-6-0, CanAM4, GISS-E2-R, HadGEM2-A, IPSL-CM5A-LR, IPSL-CM5B-LR, MIROC-ESM, MIROC5, MRI-AGCM3-2H, MRI-AGCM3-2S, MRI-CGCM3, NorESM1-M,

562 inmcm4, bcc-csm1-1-m, bcc-csm1-1, EC-EARTH, MPI-ESM-LR, MPI-ESM-MR, FGOALS-s2, FGOALS-g2, GFDL-CM3, GFDL-HIRAM-C180) and 19 from CMIP6 (BCC- 


\section{Evaluation of satellite precipitation using GTMBA raingauge data}

569 First, seasonal mean satellite precipitation data (for all seasons) were interpolated linearly to

570 the GTMBA locations. Logarithms of seasonal mean precipitation were then taken, and all 571 datasets masked at times and locations where any data (GTMBA or satellite) were missing.

572 This resulted in 1723 observations of seasonal mean precipitation from each dataset, covering the period 1998-2015 (the overlap between TRMM and GTMBA operational periods). For the remainder of the analysis, the observation location and time are ignored.

To reduce noise effectively, while retaining the signal of interest, we use the fact that precipitation tends to increase with SST, but the noise (as defined here) is largely independent of SST. For each dataset, the 1723 observations were grouped into 120 bins (14 observations per bin). This was done by ranking the observations by seasonal mean SST (the 14 observations corresponding to the 14 lowest SST values were placed in the first bin, and so on). The mean across each bin was then taken, giving 120 bin means of $\log$ (seasonal precipitation): giving 120 symbols in Figure 1. 120 bins were chosen, as a mean over 14 observations is sufficient to reduce noise significantly, while retaining a large number of symbols in Figure 1 to assess the method visually. Doubling the number of bins has negligible effect on the gradient in Figure 1. Results are insensitive to which SST dataset is used to bin the data (compare Extended data Figure 4, bottom two rows, with Figure 1). justification in Methods subsection 'Estimating regression dilution bias' below). We do this 
data Figure 4, top left), then GPCP against TRMM (Extended data Figure 4, top right). The product of the two regression gradients is 0.98 (close to 1), suggesting that this bias is small.

We also tested sensitivity of the validation to potential undercatch by the GTMBA raingauges in windy conditions ${ }^{29}$. This issue could only bias the gradients in Figures $1 \mathrm{a}, \mathrm{b}$ if the percentage undercatch varied systematically from low to high precipitation (because Figure 1 shows log precipitation). To test this, we recalculated the gradients in Figures 1a,b, but after masking the data according to the seasonal mean wind speed (also observed by GTMBA buoys). Gradients calculated for low wind $(0-4 \mathrm{~m} / \mathrm{s} ; 22 \%$ of all data) and high wind (6-10 $\mathrm{m} / \mathrm{s} ; 27 \%$ of all data) show no significant differences from Figure 1a,b (for TRMM, confidence intervals consistently spanning 1 and best estimate within $5 \%$ of 1 ; for GPCP, confidence intervals consistently excluding 1). This suggests that the satellite validation is insensitive to wind undercatch.

\section{Figure 2 data preparation (regions, seasons, time periods)}

For Figure 2, all data is first regridded by area-averaging to a common grid (resolution: $1.25^{\circ}$ latitude by $1.875^{\circ}$ longitude).

The El Niño/La Niña ratio is based on large ENSO episodes in years both simulated by the models and observed by TRMM: the 1997-1998 El Niño divided by the mean of 1998-1999 and 1999-2000 La Niñas, for the El Niño peak season (November-January), averaged over $10 \mathrm{~S}-10 \mathrm{~N}$.

Other data are zonal means over the following longitude bands (with land masked out): (Atlantic) 70W-25E; (East Pacific) 150-100W; (Indian Ocean) 50-100E.

Seasonal cycles over Atlantic and Pacific are calculated as the zonal mean for AugustOctober divided by the zonal mean for February-April). These seasons were chosen because 
they show large differences in SST, but small differences in solar zenith angle (the latter can affect precipitation by altering land temperature).

614 Spatial patterns are calculated, for each model/observational dataset, as the zonal mean at each latitude, divided by the maximum, zonal mean for the same model/observational dataset. This was calculated for August-October (ASO) for the Atlantic, due to the large meridional SST gradient for this season. November-April was used for the Indian Ocean, as this basin has a significant meridional SST gradient for this period.

\section{Estimating kqsat, part 1: data preparation}

$\mathrm{k}_{\mathrm{qsat}}$ is used here specifically to rank the models and compare with observations. Therefore, the method of calculation needs to be consistent across models and observations, and to minimise the potential for observational error.

For each year, for a given season, the logarithm of seasonal mean precipitation is calculated.

The spatial pattern of climatological mean precipitation (Extended data Figure $2 \mathrm{j}$ ) is dominated by a small area of large precipitation (occupying around $10 \%$ of the area). Hence, if we evaluated $\mathrm{k}_{\mathrm{qsat}}$ without taking the logarithm, our result would be dominated by this small area of the tropics. The spatial distribution of $\log$ (precipitation) is much more uniform (Extended data Figure 2k), except for the driest 10\% of the tropics (which is eliminated from our analysis as we mask the region of coolest SST). Hence, using log(precipitation) to calculate $\mathrm{k}_{\mathrm{qsat}}$ ensures that the result is influenced fairly equally by all parts of our analysis region (confirmed in Figure 3a). Our results use seasonal mean precipitation. Use of other timescales would alter $\mathrm{k}_{\mathrm{qsat}}$, due to the (nonlinear) logarithm in Equation 1. is regridded linearly to the high resolution TRMM horizontal grid. 
635 Before estimating $\mathrm{k}_{\mathrm{q} s a t}$, to minimise observational error, we exclude the $30 \%$ of the tropical 636 oceans with the lowest climatological mean SST. An advantage of using a logarithm in 637 equation 1 is that $\mathrm{k}_{\mathrm{qsat}}$ estimates are not dominated by the narrow ITCZ region. However, it 638 could mean that error in observing the very lowest rainfall rates could cause large error in our 639 real-world estimate of $\mathrm{k}_{\mathrm{qsat}}$. Therefore we mask the regions with coolest SST on average.

640 This masking is only done in calculating $\mathrm{k}_{\mathrm{qsat}}$. It is not done in Figure 2, as the climatological means reduce observational error there.

642 At each location, anomalies relative to climatological means are calculated for each year, for 643 both $\mathrm{q}_{\text {sat }}$ and $\log ($ precipitation). Locations that have missing data in any year are excluded.

644 These data are used in the sortav method, described below.

\section{Estimating kqsat, part 2: sortav regression method}

646 Once the data is prepared as above, our regression method for estimating $\mathrm{k}_{\mathrm{qsat}}$ (denoted 647 'sortav') is applied. For python code for this method, and an illustrative example, see Code 648 Availability Statement. The sortav method is designed to prevent dominance from the SST spatial pattern associated with ENSO (an issue because ENSO features large SST anomalies in a consistent pattern). In estimating $\mathrm{k}_{\mathrm{q} s a t}$ from inter-annual variability, our aim is to reduce the 'other-processes' term in Equation 1, by averaging over different SST patterns, with different patterns of large-scale circulation anomalies. If a single SST pattern (ENSO) was allowed to dominate, this would not be effective. If standard linear regression was used, the ENSO pattern would dominate, because ENSO features large SST anomalies. In addition, tropical means of precipitation and SST can vary over time, involving different processes than those represented by $\mathrm{k}_{\mathrm{qsat}}$. Our method avoids these issues.

657 The first step sorts each year of data. Say the data has n locations and y years. For each year, 658 the $\mathrm{n}$ anomalies in $\log$ (precipitation) are sorted in order of increasing $\mathrm{q}_{\mathrm{sat}}$ anomaly. This 
659

660

661

662

663

664

665

666

667

668

669

670

671

672

673

674

675

676

677

678

679

680

produces, for each year, a vector of length $n$, with the first element corresponding to the location with the most negative $\mathrm{q}_{\text {sat }}$ anomaly, and the last element being that with the most positive $\mathrm{q}_{\text {sat }}$ anomaly. If Equation 1 was exactly true, with zero noise, each vector would be sorted in order of increasing anomaly in $\log$ (precipitation). Because of the noise (from largescale processes), this is not, in general, true. This gives y sorted vectors, each of length $n$.

We then average over the y years, to produce one mean vector of length $n$ (e.g. the $1^{\text {st }}$ element of this vector is the mean of the y precipitation anomalies found over the most negative $\mathrm{q}_{\text {sat }}$ anomaly from each year). This averaging removes much of the noise, because the noise is largely independent of $\mathrm{q}_{\text {sat. }}$ In this mean, years with large SST anomalies have the same weighting as other years, avoiding dominance by ENSO.

The same process is repeated for $\mathrm{q}_{\mathrm{sat}}$. This gives two mean vectors, each of length $\mathrm{n}$ : for anomalies in $\log \left(\right.$ precipitation) and in $\mathrm{q}_{\text {sat. }}$

The relationship between the averaged anomalies in $\log$ (precipitation) and $\mathrm{q}_{\text {sat }}$ is relatively linear in both models and observations (e.g. Extended data Figure 2a-d), suggesting that Equation 1 is a useful approximation in this context. $\mathrm{k}_{\mathrm{qsat}}$ is then estimated from these vectors, by ordinary least squares linear regression (e.g. the gradients of the best fit lines in Extended data Figure 2a-d).

To compare with our sortav method, alternative estimates of $\mathrm{k}_{\mathrm{qsat}}$ (marked OLS in Extended Data Figures 2h,7) use standard linear regression between seasonal anomalies in $\log \left(\right.$ precipitation) and $\mathrm{q}_{\mathrm{sat}}$ (without sort-averaging). 
$\mathrm{k}_{\mathrm{qsat}}{ }^{\text {(spatial) }}$ is calculated using the same method as $\mathrm{k}_{\mathrm{qsat}}$, except that it quantifies seasonal and

682

683

684

685

686

687

688

689

690

691

692

693

694

695

696

697

698

699

700

701 spatial variation in time-mean climate (in contrast with $\mathrm{k}_{\mathrm{qsat}}$, which quantifies interannual variability). First, time means are taken for each dataset and season (giving 4 season means per grid point per dataset). For each dataset and each season separately, precipitation is divided by the tropical mean, before taking logarithms. This is done to scale out model variation in the tropical mean (which is controlled by the large-scale energy budget). For $\mathrm{q}_{\text {sat, }}$, for each dataset and season separately, anomalies are taken with respect to the tropical mean. Masking, to exclude regions with low $\mathrm{q}_{\text {sat, }}$ is based on annual mean $\mathrm{q}_{\mathrm{sat}}$.

$k_{\text {qsat }}^{\text {spattemp }}$ is defined as follows:

$P / \bar{P} \approx \exp \left(k_{q s a t}^{\text {spattemp }} \cdot q_{\text {sat }}{ }^{\prime}\right)$

This approximates variation in precipitation relative to the tropical mean, driven by variation in $\mathrm{q}_{\text {sat }}$ relative to its tropical mean. The overbar represents the tropical mean for the current season of the current year, and $q_{\text {sat }}{ }^{\prime}$ is specifically the $\mathrm{q}_{\text {sat }}$ anomaly with respect to the tropical mean:

$q_{s a t}{ }^{\prime}=q_{s a t}-\overline{q_{s a t}}$

Anomalies expressed this way capture temporal and spatial variability associated with variation in local SSTs, but exclude temporal variability in tropical mean precipitation (which is constrained by the large-scale atmospheric energy budget).

$k_{\text {qsat }}^{\text {spattemp }}$ is estimated using the same approach as kqsat, but anomalies of $\log (\mathrm{P})$ and qsat are taken relative to their tropical means for the corresponding season and year (kqsat is evaluated using anomalies with respect to local climatological means for each location). 
A disadvantage of both $\mathrm{k}_{\mathrm{qsat}}{ }^{\text {(spatial) }}$ and $k_{\text {qsat }}^{\text {spatemp }}$ is that they have some sensitivity to other processes (teleconnections) associated with the specific spatial patterns in climatological mean SST (these spatial patterns are filtered out less effectively as there are only 4 seasons, compared to the 25 years of internal variability used to estimate kqsat).

\section{A lower bound for $k_{q s a t}$ using observed interannual variability}

This method (estimated lower bound on $\mathrm{k}_{\mathrm{qsat}}$ ) accounts for three forms of observational error, combined using Monte Carlo sampling.

First, systematic error in the observed magnitudes of seasonal mean SST anomalies could bias $\mathrm{k}_{\mathrm{qsat}}$. To explore this, we first estimated $\mathrm{k}_{\mathrm{qsat}}$ (with the sortav method) using TRMM precipitation, and each of the three SST datasets (HadISST, ERSST, COBE) that cover the whole TRMM operational period, giving three direct, unscaled estimates of $\mathrm{k}_{\mathrm{qsat}}$ (Extended data Table 2a).

Second, error in the SST spatial pattern will cause a low bias in $\mathrm{k}_{\mathrm{q} s a t}$ (regression dilution bias). Typical magnitudes of this bias are estimated (see more detail in Methods section 'Estimating regression dilution bias'). This is done by regressing pairs of SST datasets against each other, with regression coefficients calculated using the sortav method (as used for $\left.\mathrm{k}_{\mathrm{qsat}}\right)$. Extended data Table $2 \mathrm{~b}$ shows the results for each pair of SST datasets. The final column of Extended data Table $2 \mathrm{~b}$ gives the 6 different estimates of regression dilution bias.

Third, the TRMM operational period does not fully overlap the AMIP SST-forced model simulation period. Thus, $\mathrm{k}_{\mathrm{q} s a t}$ estimated for the TRMM period will be different from that obtained if TRMM were operational throughout the AMIP period (due to a different set of SST patterns during the TRMM and AMIP period). Estimates of typical magnitudes of this 
error were obtained using samples from coupled ocean-atmosphere simulations (Extended data Figure 7), giving 85 samples of percentage error.

727

728

729

730

731

732

10000 estimates of $\mathrm{k}_{\mathrm{qsat}}$ were then generated using Monte Carlo sampling. For each estimate, one of the three direct estimates (Extended data Table 2a) was selected at random, 'corrected' by a random selection from the 85 samples of percentage error (Extended data Figure 7), and further corrected using a random selection from the 6 estimates of regression dilution bias (Extended data Table 2b).

The lower bound of the $95 \%$ confidence interval of these 10000 estimates is then taken. We only use the lower bound for the following reason: it seems unlikely that the true regression dilution bias is weaker than the minimum value estimated here (around 10\%, Extended data Table 2b). This is because we do not expect the SST datasets to be significantly closer to the real SST than they are to each other. However, it is plausible that the regression dilution bias could be larger than estimated, so we do not quote an upper bound for $\mathrm{k}_{\mathrm{qsat}}$.

The appropriate lower bound for an atmosphere-only AMIP model may be even higher than our quoted result, as the observed $\mathrm{k}_{\mathrm{qsat}}$ value may be reduced by the effect of atmospheric internal variability on $\mathrm{SST}^{19}$. kqsat values from AMIP models are similar to or higher than from the equivalent coupled models. In contrast, this coupling issue should be small for our central estimate of $\mathrm{k}_{\mathrm{qsat}}$ (next section), as that is based on metrics where ocean dynamics (for ENSO) or forcing associated with the mean state/seasonal cycle dominate the SST differences/gradients.

\section{Central estimate of kqsat in the real world}

We start by finding where, geographically, the models are most sensitive to $\mathrm{k}_{\mathrm{qsat}}$. This is done using correlation coefficients ( $\mathrm{r}$ ) between $\mathrm{k}_{\mathrm{qsat}}$ and the log of precipitation ratios 
748 (Extended data Figure 5) for each latitude (or longitude for ENSO) in each panel in Figure

749

750

751

752

753

754

755

756

757

758

759

760

761

762

763

764

765

766

767

768

769

770

771

2. This reveals six discrete intervals (shaded in Figure 2) where $|r|>0.6$ (about 50\% variance explained), and a seventh, showing weaker correlations, over the Indian Ocean. For each model, we average the log of precipitation ratios over each interval, and take the difference from the equivalent value for TRMM. This gives seven error indices for each model (y-axes in Extended data Figure 6). For each interval, the 28 model error indices are regressed against $\mathrm{k}_{\mathrm{qsat}}\left(\mathrm{x}\right.$-axes in Extended data Figure 6), and $\mathrm{k}_{\mathrm{qsat}}$ is estimated from where the line of best fit crosses zero error. This gives seven estimates of $\mathrm{k}_{\mathrm{qsat}}$; their mean is our central estimate.

We did not use the coupled ocean-atmosphere models to estimate $\mathrm{k}_{\mathrm{qsat}}$, due to the evident residual biases from SST error in these models, and because it isn't possible to use the ENSO response for coupled models, due to model differences in simulations of ENSO SST responses.

\section{Estimating regression dilution bias}

Regression dilution bias ${ }^{51}$ arises when there is random error in the independent variable (e.g. $\mathrm{q}_{\mathrm{sat}}$ in estimating $\left.\mathrm{k}_{\mathrm{qsat}}\right)$. This causes the regression gradient to be biased low. This bias reduces the gradient by a factor $(\beta)$ that depends only on the characteristics of the independent variable. We estimate typical magnitudes of this bias using different observations of the independent variable (e.g. different SST datasets), as follows.

Say the vector of true values of the independent variable is $\mathbf{x}$, and we have two different observational estimates, $\mathbf{x} \mathbf{1}$ and $\mathbf{x} 2$. We first regress $\mathbf{x} 1$ against $\mathbf{x} 2$. This regression uses the same methodology as when regressing the dependent variable against $\mathbf{x}$ : i.e. for estimating dilution bias in observations of $\mathrm{k}_{\mathrm{qsat}}$, the sortav method is applied; and for the satellite precipitation validation, the SST binning is used. The regression gradient $\left(\mathrm{f}_{12}\right)$ obtained from 
regressing $\mathbf{x} \mathbf{1}$ against $\mathbf{x} \mathbf{2}$, will be biased low by a factor $\beta_{2}$ (from error in $\mathbf{x} \mathbf{2}$ ). We then regress $\mathbf{x} 2$ against $\mathbf{x} 1$. This regression gradient $\left(f_{21}\right)$ will be biased low by a factor $\beta_{1}$ (from error in $\mathbf{x 1 )}$.

We then estimate the dilution bias as:

$\beta \approx \operatorname{sqrt}\left(\beta_{2} \cdot \beta_{1}\right)=\operatorname{sqrt}\left(f_{12} \cdot f_{21}\right)$

(with no dilution bias, $\mathrm{f}_{12} \cdot \mathrm{f}_{21}=1$, by definition).

This method assumes that the errors in $\mathbf{x} \mathbf{1}$ and $\mathbf{x} \mathbf{2}$ are independent.

\section{Column dry static energy budget (DSE)}

Dry static energy (DSE) is given by $\mathrm{s}=\mathrm{c}_{\mathrm{p}} \mathrm{T}+\mathrm{gz}$, where $\mathrm{c}_{\mathrm{p}}$ is the specific heat at constant pressure, $\mathrm{T}$ is the temperature, $\mathrm{g}$ is the gravitational acceleration, and $\mathrm{z}$ is altitude). DSE is affected by advection, precipitation, radiation and sensible heat:

$-\left\langle\omega \frac{\partial s}{\partial p}\right\rangle-\langle v \cdot \nabla s\rangle+L P+R+Q_{t u r b}=0$,

where $\omega$ is the vertical pressure velocity, $\mathrm{p}$ is pressure, $\mathrm{v}$ is horizontal wind. Angle brackets represent the mass-weighted vertical integral from 1000-100hPa. The first term represents import of DSE via column-integrated vertical advection; the second is horizontal advection. $\mathrm{P}$ is the total surface precipitation and $\mathrm{L}$ the latent heat of condensation; $\mathrm{R}$ is net radiation into the atmospheric column; and $\mathrm{Q}_{\text {turb }}$ is the surface sensible heat flux.

\section{Methods References}

51. Hutcheon, J. A., Chiolero, A. \& Hanley, J. A. Random measurement error and regression dilution bias. Br. Med. J. 340, (2010). 
795 Data availability

796 Datafiles with estimates of $\mathrm{k}_{\mathrm{qsat}}$ for models and observations, along with sample plotting 797 code, are available from http://doi.org/10.5281/zenodo.3878691. Data from the integration of 798 CNRM-CM6 with the CM5 convection scheme (denoted CNRM-CM6-conv5) are available 799 from https://doi.org/10.5281/zenodo.3875005. Model and observational data is available at the 800 following websites. CMIP5: https://cmip.llnl.gov/cmip5/; CMIP6: https://esgf-

801 node.llnl.gov/projects/cmip6/; GTMBA: https:/www.pmel.noaa.gov/gtmba/; TRMM:

802 https://pmm.nasa.gov/data-access/downloads/trmm; GPCP and COBE:

803 https://www.esrl.noaa.gov/psd/; HadISST: https://www.metoffice.gov.uk/hadobs/hadisst; ERSST:

804 http://www1.ncdc.noaa.gov/pub/data/cmb/ersst/v4/netcdf/.

805 Code Availability

806 Python code for calculating $\mathrm{k}_{\mathrm{qsat}}$, including the sortav regression routine, is available from 807 http://doi.org/10.5281/zenodo.3878691. 
End Notes

Acknowledgements This work was supported jointly by the Met Office Hadley Centre Climate Programme funded by BEIS and Defra, and by the Newton Fund through the Met Office Climate Science for Service Partnership Brazil (CSSP Brazil). SSR was supported by the National Aeronautics and Space Administration Grant 80NSSC17K0227 and the Korean Meteorological Administration Research and Development Program under grant KMI2018-03110. We acknowledge the GTMBA Project Office of NOAA/PMEL for making the GTMBA data available. The QuikSCAT data were obtained from the NASA EOSDIS Physical Oceanography Distributed Active Archive Center (PO.DAAC) at the Jet Propulsion Laboratory, Pasadena, CA (http://dx.doi.org/10.5067/GHGMR4FJ01). We acknowledge NOAA/ESRL PSD for the wind profiler data. We acknowledge the World Climate Research Programme's Working Group on Coupled Modelling, which is responsible for CMIP, and we thank the climate modelling groups (listed in Methods) for producing and making available their model output. For CMIP the U.S. Department of Energy's Program for Climate Model Diagnosis and Intercomparison provides coordinating support and led development of software infrastructure in partnership with the Global Organization for Earth System Science Portals. GPCP data provided by the NOAA/OAR/ESRL PSD, Boulder, Colorado, USA, from their Web site at https://www.esrl.noaa.gov/psd/. COBE-SST2 data provided by the NOAA/OAR/ESRL PSD, Boulder, Colorado, USA, from their Web site at https://www.esrl.noaa.gov/psd/

831 Author Contributions P.G. conceived and designed the study and performed the analysis. All 832 authors contributed to scientific interpretation and wrote the manuscript. R.R. performed the 
833 CNRM model simulations. P.G., R.C., C.E.H. and R.R. contributed understanding on physical

834 processes. J.K. provided knowledge of SST observational uncertainty and datasets.

835 Author Information Reprints and permissions information is available at www.nature.com/reprints.

836 The authors have no competing financial interests. Correspondence and requests for materials

837 should be addressed to peter.good@metoffice.gov.uk.

838

839

840

841 


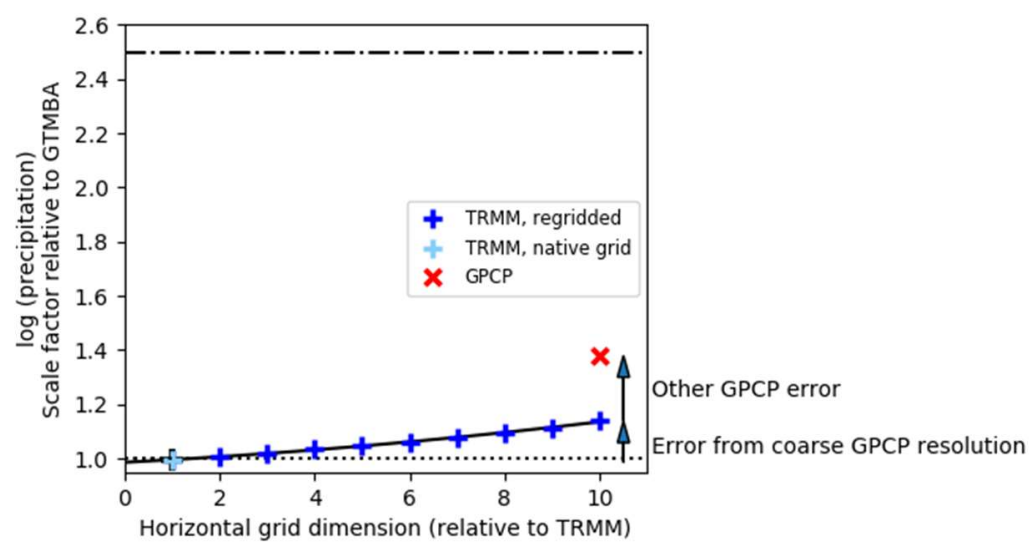

847 Extended data Figure 1. Effect of low spatial resolution in GPCP satellite observations of $\log$ (seasonal precipitation). $\mathrm{y}$-axis: regression gradient in validation against GTMBA raingauge data (i.e. gradients in Figure 1 for light blue and red symbols). $\mathrm{x}$-axis: horizontal grid dimension relative to TRMM (e.g. the TRMM resolution is $0.25^{\circ}$, ten times smaller than the GPCP resolution of $2.5^{\circ}$, so the red symbol is placed at $\mathrm{x}=10$ ). Dark blue symbols: results when TRMM data is regridded (by area averaging) to coarser grids. The coarser grids are chosen so the grid box edges overlap edges of the native TRMM grid. To give the errors context, the dash-dot line marks the ratio between the largest and smallest model values of $\mathrm{k}_{\mathrm{qsat}}(2.5)$. Solid black line is a quadratic least-squares best fit line through the TRMM-based data. The intercept of the TRMM best-fit curve at $x=0$ (i.e. infinitely fine grid) is very close to the value estimated on the TRMM native grid (light blue symbol), indicating that the TRMM grid is sufficiently fine for comparison with the rangauge data on seasonal timescales. 

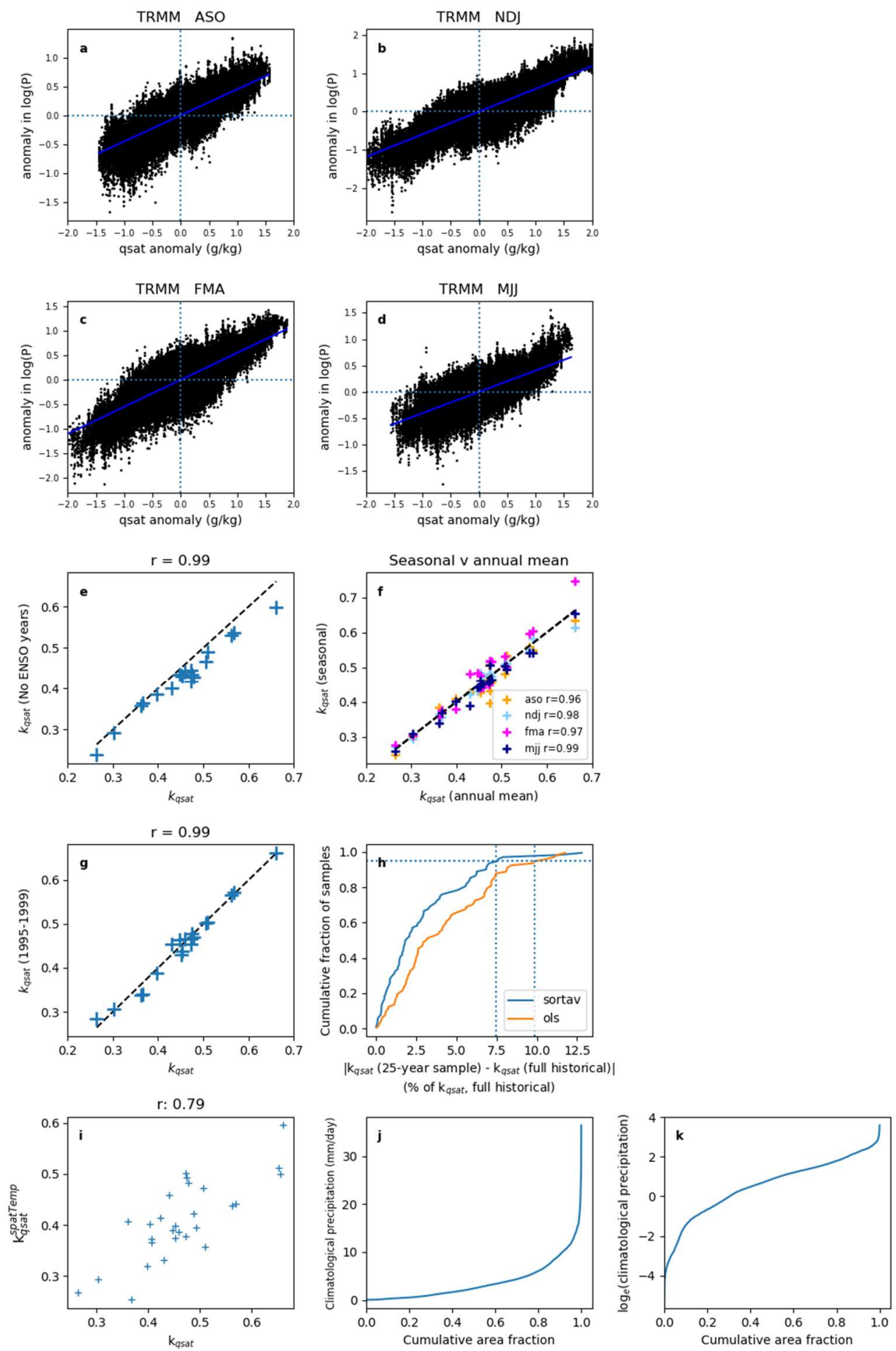

863 Extended data Figure 2. Testing the method of estimating $\mathrm{k}_{\mathrm{qsat}}$. a-d: example results of the

864 sortav method for TRMM precipitation and HadISST SST, for different seasons: mean

865 vectors of anomalies in (y-axis) $\log$ (precipitation) and ( $\mathrm{x}$-axis) $\mathrm{q}_{\mathrm{sat}}$; $\mathrm{k}_{\mathrm{qsat}}$ is given by the gradient of the blue best-fit regression line. e, y-axis: $\mathrm{k}_{\mathrm{qsat}}$ calculated after excluding the 9 
867 years with the largest absolute value of the nino3.4 index; $\mathrm{x}$-axis: default $\mathrm{k}_{\mathrm{qsat}}$ (one symbol

868 per model); $\mathrm{k}_{\mathrm{qsat}}$ is on average 6\% lower when ENSO years excluded, due to a small

869 sensitivity to the ENSO characteristic spatial pattern; but the model ranking is largely

870 unchanged $(\mathrm{r}=0.99)$. $\mathbf{f}, \mathrm{k}_{\mathrm{qsat}}$ calculated for individual seasons versus the annual mean value;

$871 \quad \mathbf{g ~ k}_{\mathrm{qsat}}$ using only years 1995-1999 versus the full 25-year estimate; $\mathbf{h}$, estimating variability

872 (due to internal variability in SST patterns) in $\mathrm{k}_{\mathrm{qsat}}$ estimated from 25 years of data: for each

873 coupled ocean-atmosphere model, $\mathrm{k}_{\mathrm{qsat}}$ is estimated both for the full historical run, and for all

874 25-year chunks. Panel shows the cumulative distribution function of absolute percentage

875 differences between the 25 -year estimates and the full estimates $(95 \%$ of samples are within

$8768 \%$ of the long-term value from the full historical run). This panel shows results for two

877 methods of estimating $k_{\text {qsat: }}$ our 'sortav' method (as used throughout the manuscript), and

878 standard OLS regression between seasonal anomalies in $\log$ (precipitation) and $\mathrm{q}_{\text {sat. }} \mathbf{i}$

879 comparing $k_{\text {qsat }}^{\text {spattemp }}$ with $\mathrm{k}_{\mathrm{qsat}}$; each cross represents one CMIP5 model. $\mathbf{j}, \mathbf{k}$ Cumulative

880 distribution functions of $\mathbf{j}$ climatological mean precipitation and $\mathbf{k} \log$ (precipitation). From

881 HadGEM2-A, May-July season (same picture seen in other seasons). 

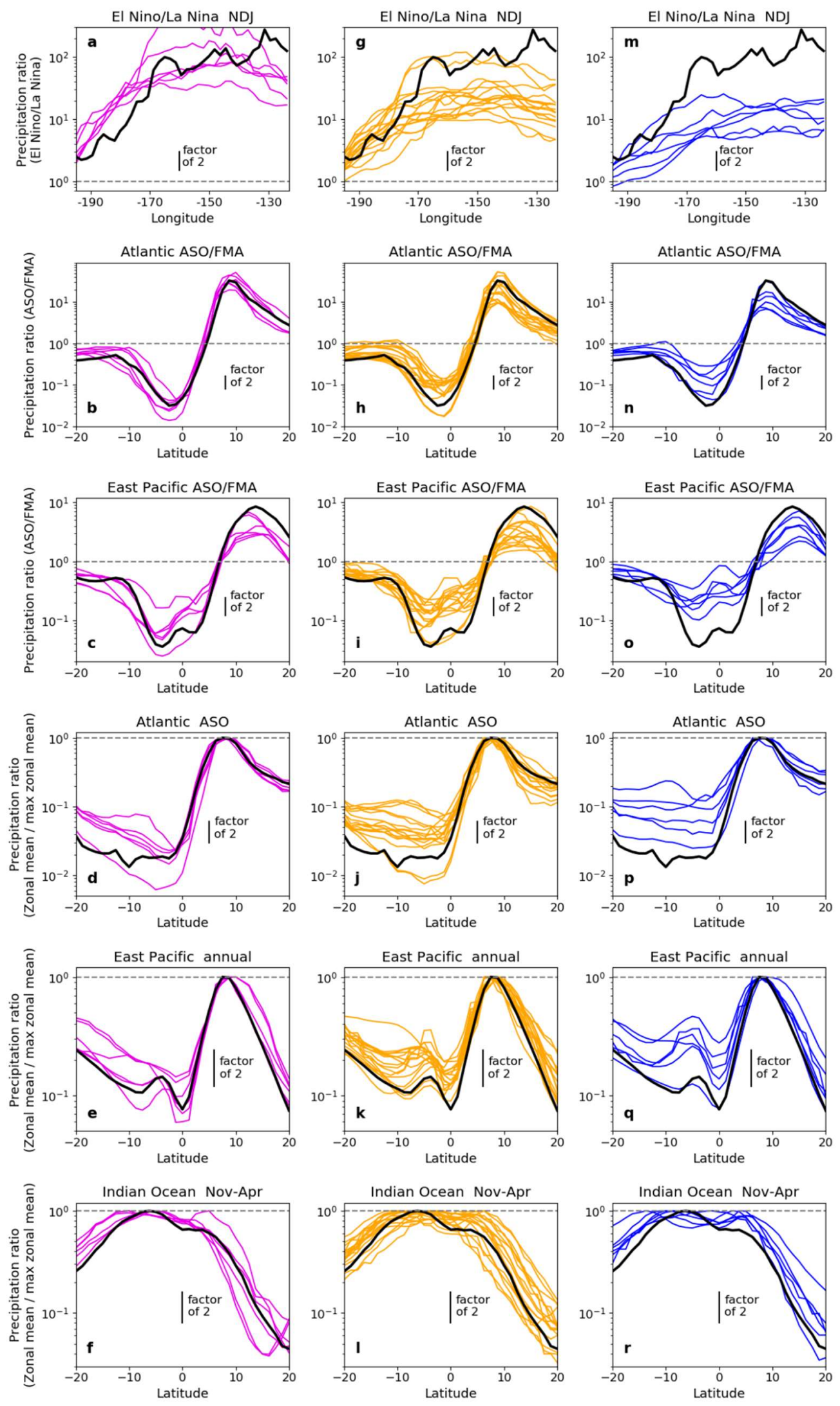

885 Extended data Figure 3. Model biases for the high, mid-range and low-kqsat models

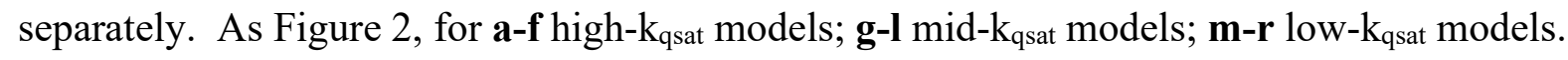


888 Extended data Figure 4. Testing potential errors in the satellite validation against GTMBA.

889 a,b testing for regression dilution bias from error in TRMM observations: as Figure 1, but for 890 a TRMM versus GPCP (both interpolated to GTMBA sites and masked as in Figure 1) and b 891 GPCP versus TRMM. c-f testing for effects of SST uncertainty on the binning: as Figure 1, 892 but using $\mathbf{c}, \mathbf{d}$ ERSST and e,f COBE SST datasets to bin the data.

893

894 

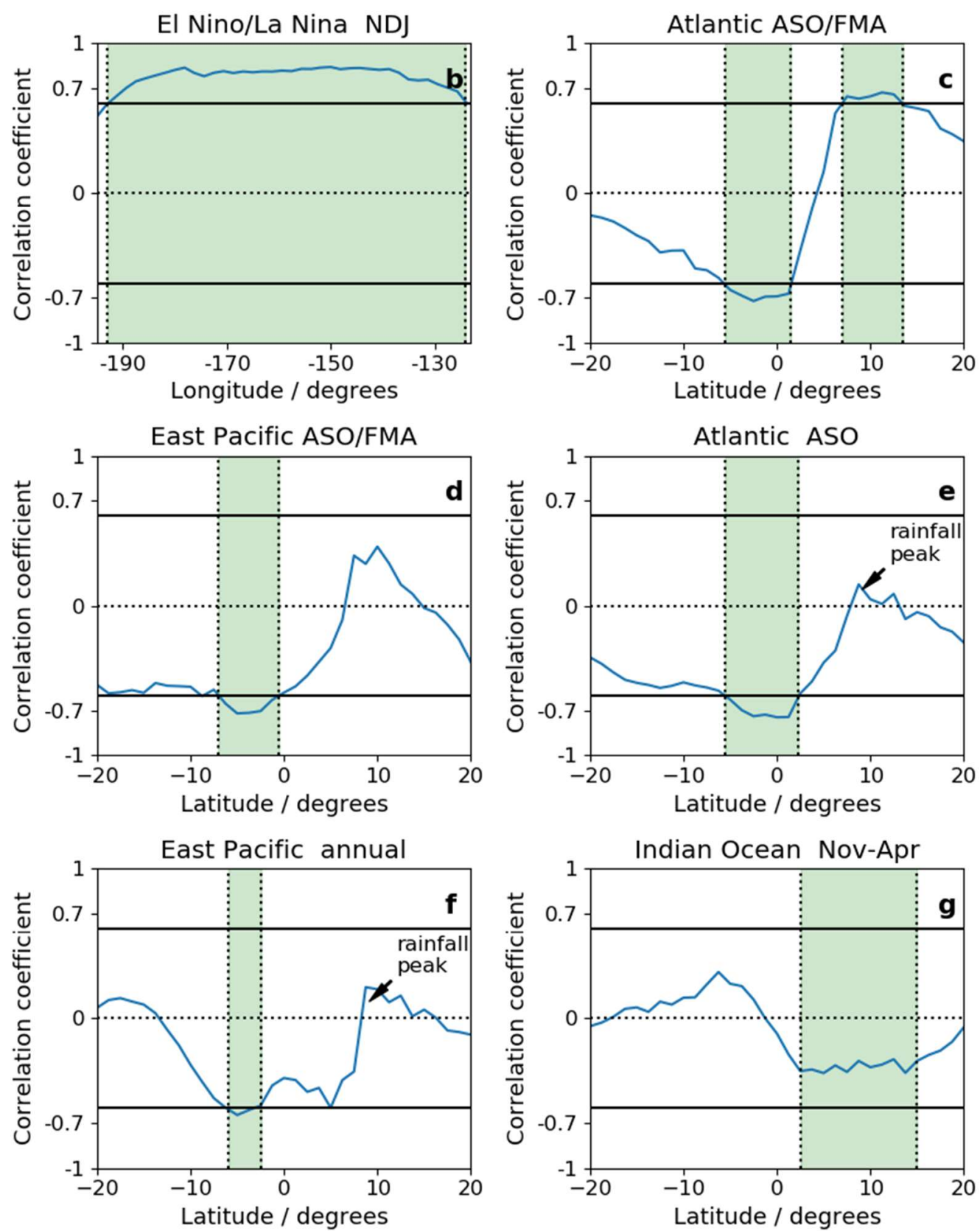

895

896 Extended data Figure 5. Regions where models are most sensitive to $\mathrm{k}_{\mathrm{qsat}}$. For each latitude

897 of each region: $y$-axis shows Pearson correlation coefficients (r) between the 28 different

898 CMIP5 model values $\mathrm{k}_{\mathrm{qsat}}$, and the 28 CMIP5 model values of the logarithm of the precipitation ratio for that latitude and region (i.e. the logarithm of the grey lines in Figure 2a-

f). Green bands mark the latitude intervals chosen to estimate the observational constraints on $\mathrm{k}_{\mathrm{qsat}}$ (a-e: intervals chosen where $|\mathrm{r}|>0.6$; $\mathbf{f}$, a band of most negative $\mathrm{r}$ is chosen). 
903 to the latitude of the precipitation peak in most models (the model spread in the precipitation

904 peak is scaled out; coefficients are not exactly zero as there is a small model spread in the 905 latitude of the precipitation peak).

906

907 

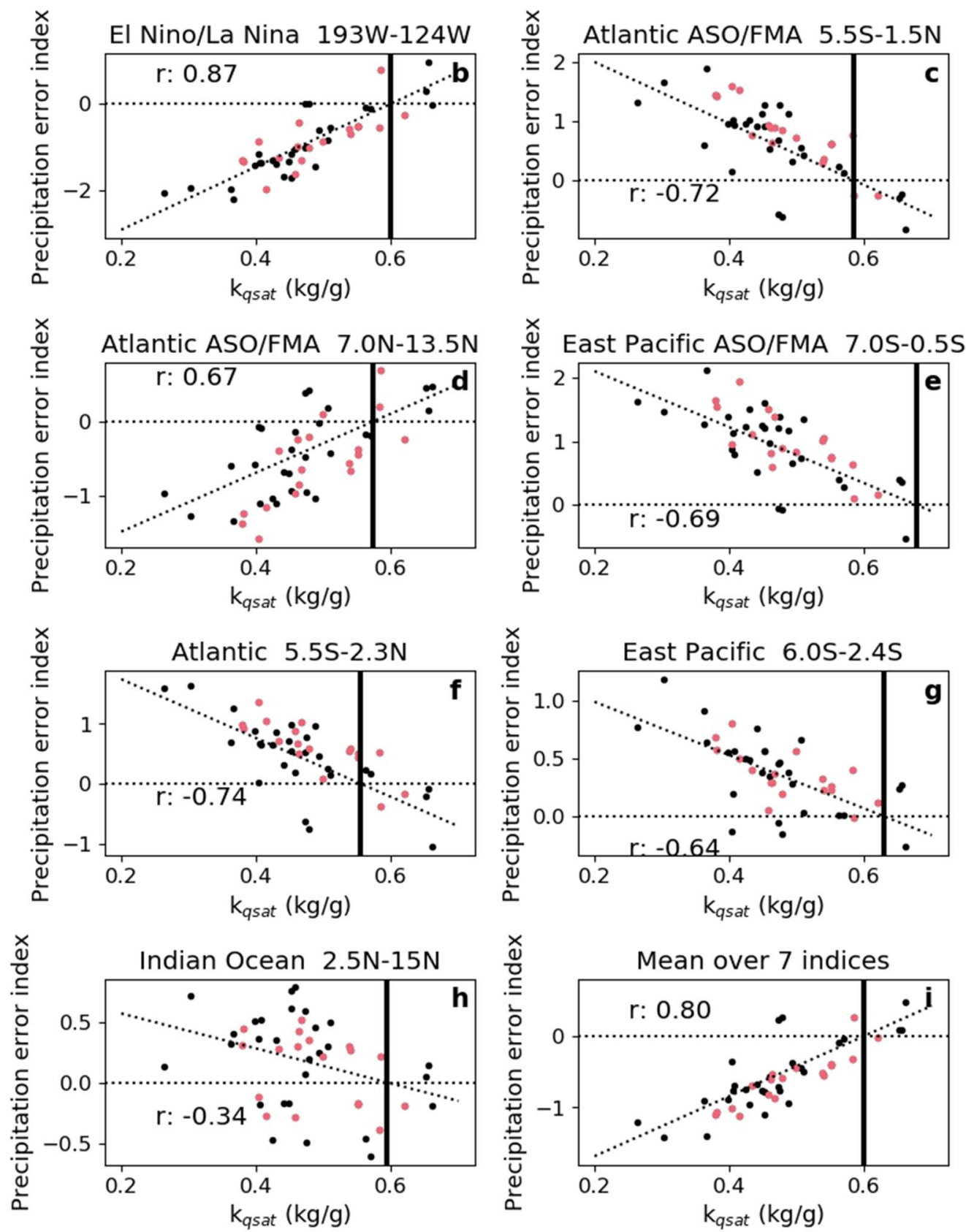

909 Extended data Figure 6. Scatter plots underpinning the central observational estimate of $\mathrm{k}_{\mathrm{qsat}}$.

910 a-g Precipitation error index versus $\mathrm{k}_{\mathrm{qsat}}$ for each of the 7 latitude intervals highlighted in

911 Figure 2. Y-axes: logarithm of precipitation ratio, averaged over each latitude band, minus

912 the equivalent value for TRMM observations, for (black) CMIP5 and (red) CMIP6 models.

913 Dotted lines: linear least-squares fits (using CMIP5 data only). Vertical black line: $\mathrm{k}_{\mathrm{qsat}}$

914 estimate for each latitude interval, from the intercept of the green line with zero error index

915 (dotted line). $\mathbf{h}$ Mean precipitation error index versus $\mathrm{k}_{\mathrm{qsat}}$ : mean error index is averaged over 
916 the 7 indices in the other panels (after the signs of the 5 indices with negative best-fit slopes

917 were changed, to ensure a positive correlation with $\mathrm{k}_{\mathrm{qsat}}$ ).

918

919 


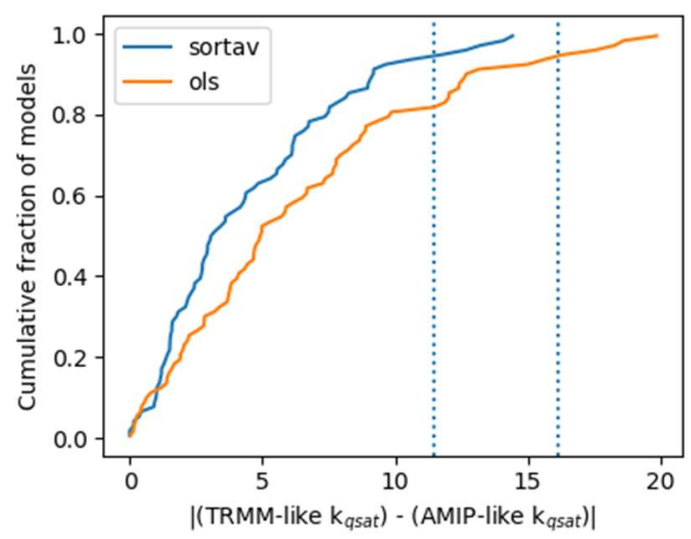

920

(\% of AMIP-like $k_{\text {qsat }}$ )

921 Extended data Figure 7. Supporting results for observational estimate of the $\mathrm{k}_{\mathrm{qsat}}$ lower

922 bound. Estimating error, from internal variability, due to the fact that the TRMM operational

923 period only partly overlaps the time period simulated by the AMIP SST-forced models. Error

924 magnitudes are estimated from the coupled ocean-atmosphere simulations, using differences

925 between $\mathrm{k}_{\mathrm{qsat}}$ estimated from all possible overlapping 17-year (TRMM-like) and 25-year

926 (AMIP-like) periods (with the same overlap as TRMM and the 25-year SST-forced model

927 simulations). Results are given for two methods of estimating $\mathrm{k}_{\mathrm{qsat}}$ : our 'sortav' method (as

928 used throughout the manuscript), and standard OLS regression between seasonal anomalies in

$929 \log ($ precipitation $)$ and $\mathrm{q}_{\text {sat. }}$

930

931 

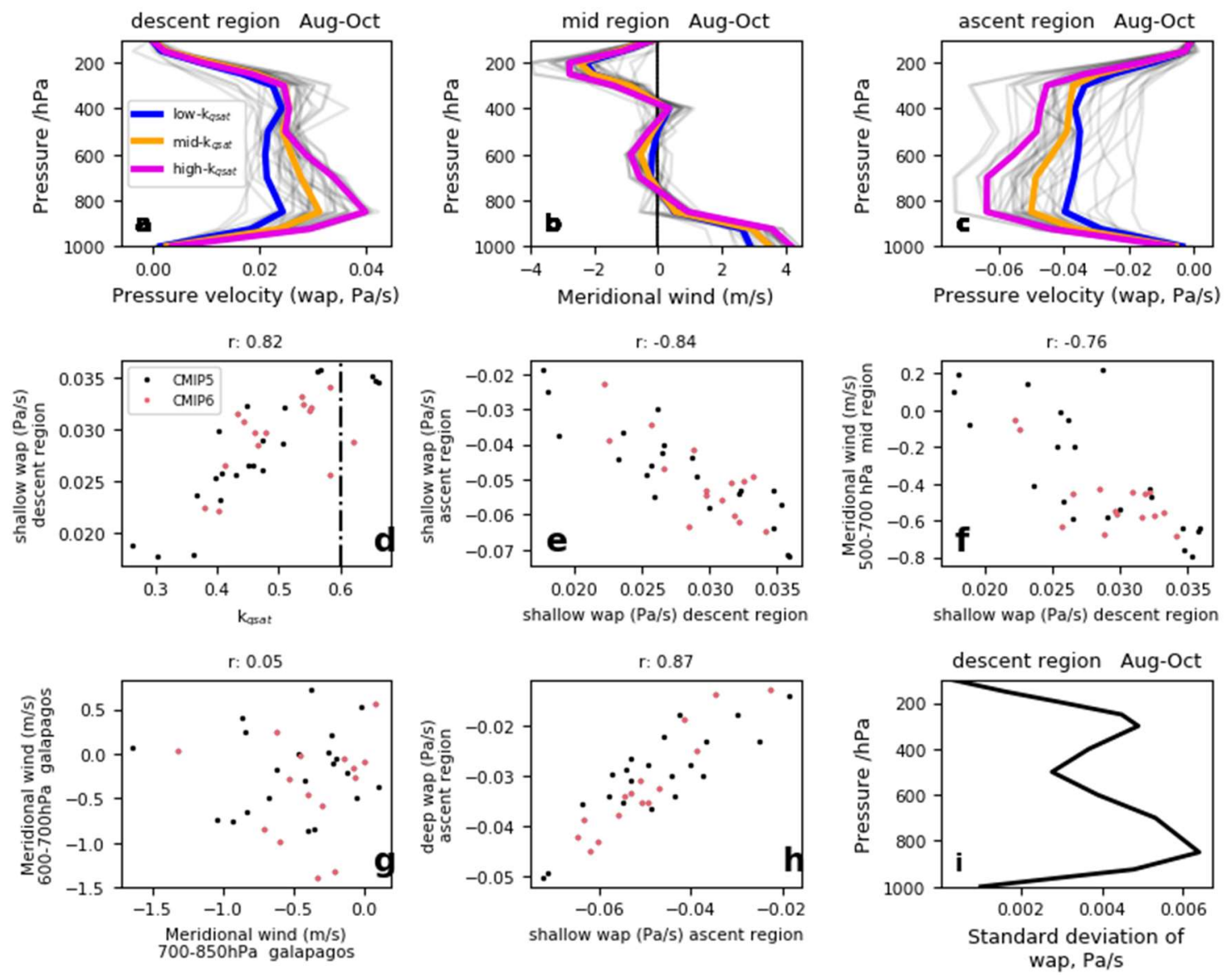

933 Extended Data Figure 8. Atmospheric circulation measures in CMIP5 and CMIP6 models. a-c thick lines are CMIP5 composite means, for (magenta) high $\mathrm{k}_{\mathrm{qsat}}$ subset; (blue) low $\mathrm{k}_{\mathrm{qsat}}$ subset and (gold) intermediate $\mathrm{k}_{\mathrm{qsat}}$. Thin grey lines are individual models (CMIP5 and CMIP6). Descent (5S-1N), mid (1-7N) and ascent (7-13N) regions are marked by vertical dotted lines in Figure 5c-e. d-h: each symbol represents one CMIP5 (black) or CMIP6 (red) model. Title gives Pearson correlation coefficient. $\mathbf{d}$ shallow descent versus $\mathrm{k}_{\mathrm{qsat}}$; vertical line marks our best estimate of $\mathrm{k}_{\mathrm{qsat}}$. $\mathrm{e}$ shallow ascent versus shallow descent. $\mathbf{f}$ shallow meridional return flow versus shallow descent. $\mathbf{g}$ shallow versus very-shallow meridional wind, over Galapgos: the negligible correlation indicates different physical processes at these two levels. $\mathbf{h}$ deep versus shallow ascent. i standard deviation, across models, of the pressure velocity (wap) at each pressure level. 


\begin{tabular}{|c|c|c|c|c|}
\hline Descent region, column integrals & $\begin{array}{l}\text { High } k_{\text {qsat }} \\
\text { mean }\end{array}$ & $\begin{array}{l}\text { Mid } k_{\text {qsat }} \\
\text { mean }\end{array}$ & $\begin{array}{l}\text { Low } k_{\text {qsat }} \\
\text { mean }\end{array}$ & $\begin{array}{l}\text { High } k_{\text {qsat }}- \\
\text { Low } k_{\text {qsat }}\end{array}$ \\
\hline Net radiation + sensible heat flux & -129.4 & -125.9 & -127.5 & -1.8 \\
\hline Latent heating by precipitation & 14.4 & 22.9 & 35.5 & -21.1 \\
\hline $\begin{array}{l}\text { Vertical advection by mean vertical } \\
\text { velocity, integrated over 100-1000 } \\
\mathrm{hPa}\end{array}$ & 130.1 & 110.0 & 95.5 & 34.6 \\
\hline $\begin{array}{l}\text { Vertical advection by mean vertical } \\
\text { velocity, integrated over } 600-1000 \\
\mathrm{hPa}\end{array}$ & 74.5 & 57.4 & 48.1 & 26.4 \\
\hline Residual advection & -15.1 & -7.0 & -3.5 & -11.6 \\
\hline
\end{tabular}

948

949 Extended Data Table 1. Column-integrated dry static energy budget for the descent region,

950 Aug-Oct, averaged over the high-, mid- and low- $\mathrm{k}_{\mathrm{qsat}}$ groups of CMIP5 models. Vertical

951 advection by mean vertical velocity is calculated using seasonal mean vertical velocity. The

952 final row, calculated as a residual from the first three columns, includes horizontal advection,

953 and vertical advection by transient eddies.

954 


\begin{tabular}{|l|l||}
\hline a SST dataset & Unscaled kqsat estimate (no bias correction) \\
\hline HadISST & 0.58 \\
\hline ERSST & 0.49 \\
\hline COBE & 0.51 \\
\hline \hline
\end{tabular}

\begin{tabular}{|l|l|l|l|l||}
\hline \hline b SST1 & SST2 & K1 $(\mathbf{X}=$ SST1 $)$ & K2 $(\mathbf{X}=$ SST2) & SQRT(K1*K2) \\
\hline AMIP & HadISST & 0.77 & 1.01 & 0.89 \\
\hline AMIP & COBE & 0.85 & 1.00 & 0.92 \\
\hline AMIP & ERSST & 0.76 & 0.97 & 0.86 \\
\hline HadISST & COBE & 0.76 & 0.79 & 0.78 \\
\hline HadISST & ERSST & 0.83 & 0.55 & 0.68 \\
\hline COBE & ERSST & 0.92 & 0.54 & 0.70 \\
\hline
\end{tabular}

957

958 Extended data Table 2. Supporting results for observational estimate of the $\mathrm{k}_{\mathrm{qsat}}$ lower bound 959 (see Methods for details). a Unscaled estimates for $\mathrm{k}_{\mathrm{qsat}}$ directly estimated using TRMM 960 precipitation and three different SST datasets (the AMIP SST dataset was not used due to

961 limited temporal overlap with the TRMM operational period). These values are

962 contaminated by regression dilution bias so do not represent central estimates. b Estimating

963 typical values of regression dilution bias from each pair of SST datasets. K1 is the gradient

964 from linear regression when regressing SST1 against SST2 (using the sortav regression method). K2 is the value obtained when regressing SST2 against SST1. 